\title{
T-induced displacive phase transition of end-member Pb-lawsonite
}

\author{
Martin Ende ${ }^{1, *}$, Bernd Wunder $^{2}$, Monika Koch-Müller $^{2}$, Thomas PipPinger $^{1}$, Gernot Buth ${ }^{3}$, \\ Gerald Giester ${ }^{1}$, Christian L. Lengauer ${ }^{1}$ And Eugen Libowitzky ${ }^{1}$ \\ 1 Department of Mineralogy and Crystallography, University of Vienna, 1090 Vienna, Austria \\ 2 Helmholtz-Zentrum Potsdam, GFZ German Research Centre for Geosciences, 14473 Potsdam, Germany \\ 3 ANKA, Karlsruhe Institute of Technology (KIT), 76131 Karlsruhe, Germany
}

[Received 17 October 2014; Accepted 21 June 2015; Associate Editor: Mark Welch]

\section{ABSTRACT}

$\mathrm{Pb}$-lawsonite, $\mathrm{PbAl}_{2}\left[(\mathrm{OH})_{2} \mid \mathrm{Si}_{2} \mathrm{O}_{7}\right] \cdot \mathrm{H}_{2} \mathrm{O}$, space group Pbnm, was synthesized as crystals up to $15 \mu \mathrm{m} \times$ $5 \mu \mathrm{m} \times 5 \mu \mathrm{m}$ in size by a piston cylinder technique at a pressure of $\sim 4 \mathrm{GPa}$ and a temperature of $873 \pm 10 \mathrm{~K}$. Temperature-dependent powder and single-crystal X-ray diffraction (XRD) analyses partly using synchrotron radiation as well as Raman spectroscopic investigations reveal a phase transition around $445 \mathrm{~K}$ resulting in the $\mathrm{Cmcm}$ high-temperature structure. The transformation temperature is considerably higher than that of lawsonite around $273 \mathrm{~K}$, which is characterized predominantly by proton order/disorder. The transition is confirmed using principal component analysis and subsequent hierarchical cluster analysis on both the powder XRD patterns and the Raman spectra. Furthermore, a non-uniform change is observed around $355 \mathrm{~K}$, which is not as pronounced as the $445 \mathrm{~K}$ transition and apparently comes from enhanced hydrogen bonding, which stops the atom shifts in Pb-lawsonite. These are the same bonds that mainly characterize the phase transition in lawsonite around $273 \mathrm{~K}$. In contrast, the structural transition of $\mathrm{Pb}$ lawsonite at $445 \mathrm{~K}$ seems to originate from the interaction of the $\mathrm{SiO}_{4}$ tetrahedra and $\mathrm{AlO}_{6}$ octahedra framework with the $\mathrm{Pb}^{2+}$ cation. The structural environment of $\mathrm{Pb}^{2+}$ can be described by a 12 -fold coordination above $445 \mathrm{~K}$, which changes towards irregular ten-fold coordination below this temperature. An assignment of the $\mathrm{O}-\mathrm{H}$ stretching Raman bands confirms moderately strong $\mathrm{H}$ bonds in $\mathrm{Pb}$-lawsonite, whereas both strong and weak $\mathrm{H}$ bonds exist in lawsonite. Therefore, a further phase transition of $\mathrm{Pb}-$ lawsonite, similar to that of lawsonite around $273 \mathrm{~K}$, is not expected.

KeYwords: lawsonite, Pb-lawsonite, structural phase transition, principal component analysis, PCA.

\section{Introduction}

LAWSONITE-TYPE compounds $A^{+2} B_{2}^{+3}\left[(\mathrm{OH})_{2}\right.$ $\left.C_{2} \mathrm{O}_{7}\right] \cdot \mathrm{H}_{2} \mathrm{O}(A=\mathrm{Ca}, \mathrm{Sr}, \mathrm{Ba}, \mathrm{Pb} ; B=\mathrm{Al}, \mathrm{Mn}, \mathrm{Fe}$; $C=\mathrm{Si}, \mathrm{Ge})$ are high density $\left(3.09 \mathrm{~g} \mathrm{~cm}^{-3}\right.$ for lawsonite, $4.53 \mathrm{~g} \mathrm{~cm}^{-3}$ for Pb-lawsonite) hydrous disilicates (except for $\mathrm{Ge}$ ), which are stable over a broad $P-T$ field (Schmidt and Poli, 1994; Daniel et al., 1999; Pawley and Allan, 2001). Mostly, chains of $\mathrm{AlO}_{6}$ octahedra plus $\mathrm{Si}_{2} \mathrm{O}_{7}$ dimers build up a

* E-mail: martin.ende@univie.ac.at

DOI: 10.1180/minmag.2016.080.015 mixed polyhedral framework, in which large $A$ cations, $\mathrm{OH}^{-}$groups and $\mathrm{H}_{2} \mathrm{O}$ molecules fill the structure voids (Fig. 1). Because of the high $\mathrm{H}_{2} \mathrm{O}$ content and its extensive structural stability at high pressure, lawsonite $\left(\mathrm{CaAl}_{2}\left[(\mathrm{OH})_{2} \mid \mathrm{Si}_{2} \mathrm{O}_{7}\right] \cdot \mathrm{H}_{2} \mathrm{O}\right)$ sensu stricto is considered a potential carrier for $\mathrm{H}_{2} \mathrm{O}$ into the subduction zones of the Earth (Daniel et al., 1999; Brovarone and Beyssac, 2014). In the last two decades, more and more lawsonite-type compounds with different compositions have been found in nature, i.e. hennomartinite $\left(\mathrm{Sr}-\mathrm{Mn}^{3+}-\right.$ silicate; Armbruster et al., 1993), noélbensonite $\left(\mathrm{Ba}-\mathrm{Mn}^{3+}\right.$-silicate; Kawachi and Coombs, 1996), itoigawaite (Sr-Al-silicate; Miyajima et al., 1999), 


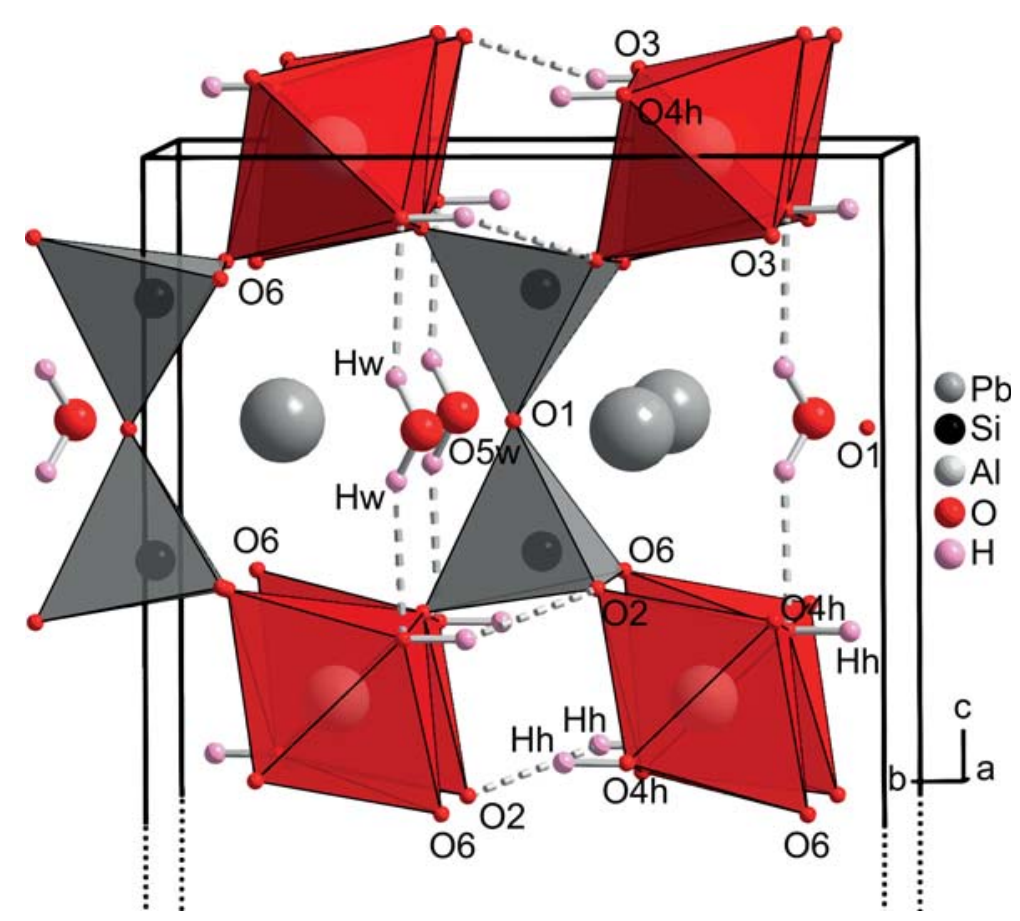

FIG. 1. Part of the unit cell of $\mathrm{Pb}$-lawsonite, space group $\mathrm{Pbnm}$, at room temperature. Broken grey lines indicate $\mathrm{H}$ bonds with $\mathrm{H}^{\cdots} \mathrm{O}$ distances of 1.95 to $2.06 \AA$.

Cr-lawsonite (Ca-(Al,Cr)-silicate, Mevel and Kienast, 1980; Sherlock and Okay, 1999), and more recently bartelkeite $(\mathrm{Pb}-\mathrm{Fe}$-germanate; Origlieri et al., 2012). Libowitzky and Armbruster (1995) found that lawsonite shows phase transitions at 273 and $150 \mathrm{~K}$. These transitions mainly involve changes in the positions of the hydrogen atoms and their immediate neighbours together with modifications in the hydrogen-bond scheme. Libowitzky and Rossman (1996) indicated dynamically disordered hydroxyl groups and $\mathrm{H}_{2} \mathrm{O}$ molecules for the room temperature $\mathrm{Cmcm}$ structure of lawsonite. By referring to the smooth changes of stretching and bending frequencies in infrared (IR) spectra across the phase boundaries they suggested a phase transition of a dynamic order-disorder type.

After successful synthesis and characterization of Sr-lawsonite (Liebscher et al., 2010), $\mathrm{Pb}$-lawsonite was first synthesized and structurally characterized using powder samples by Dörsam et al. (2011). The aim of the present paper is to present single-crystal structure data and to trace the temperature-dependent structural transformations of $\mathrm{Pb}$-lawsonite using Raman spectroscopic and powder XRD measurements, including principal component analysis (PCA) and subsequent cluster analysis on both data sets. In addition, the structures of the high-temperature phases were investigated by single-crystal and powder XRD.

\section{Synthesis and experiments}

For synthesis of $\mathrm{Pb}$-lawsonite Dörsam et al. (2011) used a mixture of $\alpha$-quartz, $\gamma-\mathrm{Al}_{2} \mathrm{O}_{3}, \mathrm{PbO}$ and $\mathrm{NaCl}$ in water. In our study the starting material used was an amorphous glass with stoichiometric $\mathrm{Pb}$ lawsonite cation composition $\left(\mathrm{PbAl}_{2} \mathrm{Si}_{2} \mathrm{O}_{\mathrm{x}(7-8)}\right)$ and microporous properties (micro- to nanoparticles sintered in a spongy structure), aimed at obtaining faster growth rates compared to Dörsam et al. (2011), who produced only fine-grained material in their experiments.

The stoichiometric glass was synthesized using the Pechini or citrate gel method (Pechini, 1967; Raab, 2010) with slightly more than $0.03 \mathrm{M}$ tetraethyl orthosilicate $\left(\mathrm{C}_{8} \mathrm{H}_{20} \mathrm{O}_{4} \mathrm{Si}\right)$ as the silicon source. Furthermore, $0.03 \mathrm{M}$ of citric acid and $0.06 \mathrm{M}$ of ethylene-glycol were used to produce around $0.015 \mathrm{M}$ of the precursor phase with $0.03 \mathrm{M} \mathrm{Al}\left(\mathrm{NO}_{3}\right)_{3} \cdot 9 \mathrm{H}_{2} \mathrm{O}$, $\mathrm{Pb}\left(\mathrm{NO}_{3}\right)_{2}$ and $0.015 \mathrm{M}$ tetraethyl-orthosilicate at $438 \mathrm{~K}$ for $12 \mathrm{~h}$. The resulting precursor phase was milled and calcined at $923 \mathrm{~K}$ for $12 \mathrm{~h}$. The glass 
was sealed together with excess water in Au capsules $10 \mathrm{~mm} \times 2 \mathrm{~mm} \times 2 \mathrm{~mm}$ in size, compressed at $4 \mathrm{GPa}$, heated within $30 \mathrm{~min}$ to $\sim 873 \mathrm{~K}$ and kept constant under these conditions for $\sim 120 \mathrm{~h}$. A standard piston cylinder apparatus with $\mathrm{NaCl}$ assembly and steel furnace was used. Pressure could be controlled within $\pm 50 \mathrm{MPa}$ and temperature was recorded with a Ni-Cr-Ni thermocouple with an accuracy of $\pm 10 \mathrm{~K}$, based on calibrations with reference substances. The thermocouple was placed close to the centre of the capsule.

\section{Experimental}

\section{Raman spectroscopy}

Powder samples with a grain size of $<1 \mu \mathrm{m}$ were used. Spectra were acquired with a Renishaw RM1000 micro-Raman spectrometer with a $20 \mathrm{~mW} \quad 632.8 \mathrm{~nm}$ HeNe laser, a $1200 \mathrm{~mm}^{-1}$ grating, and a thermoelectrically cooled CCD detector. All measurements were accomplished with a resolution of $\sim 2.5 \mathrm{~cm}^{-1}$. Spectra were measured in $180^{\circ}$ back-scattering geometry on a Linkam (THMS 600) cooling-heating stage using a 20x/0.40 long distance objective. The precision of the measured temperature of the stage is $\sim 0.1 \mathrm{~K}$, but the temperature of the sample may differ over a range of $5 \mathrm{~K}$ according to its size, its position on the stage and the influence of the supporting glass plate. The laser power at the sample was reduced to $\sim 3 \mathrm{~mW}$ to avoid heating the sample, and the glass plate was mounted on the silver block of the cooling-heating stage. The system was calibrated to the Rayleigh line and the Raman line of a silicon wafer with respect to the stress-free value of $520 \mathrm{~cm}^{-1}$. Based on low laser power and very small sample amounts the measurements were started at room temperature with $2 \times 20 \mathrm{~min}$ and were increased every $5 \mathrm{~K}$ to $\sim 2 \times 30 \mathrm{~min}$ at $573 \mathrm{~K}$.

For evaluation of Raman band positions and peak widths (full width at half maximum, FWHM) a pseudo-Voigt function with a free mixing factor of Gauss and Lorentz components was used to fit the bands. In addition a multivariate statistical technique, principal component analysis (PCA; Pearson, 1901) plus subsequent hierarchical cluster analysis were performed. PCA for Raman spectroscopy, for example, was successfully applied by Sato-Berru et al. (2007) and MejíaUriarte et al. (2012) for the characterization of $\mathrm{BaTiO}_{3}$ phase transitions.

\section{Single-crystal diffraction and powder X-ray diffraction}

The room temperature single-crystal structure analysis was performed using a Bruker Kappa Apex II diffractometer with a CCD detector and an Incoatec Microfocus Source I $\mu \mathrm{S}(30 \mathrm{~mW}$, multilayer mirror, $M o K \alpha, 0.71 \AA$ ). The high-temperature single-crystal XRD experiment at $370 \mathrm{~K}$ was performed at the SCD beam line at ANKA, the synchrotron radiation facility at KIT in Karlsruhe, Germany. The chosen wavelength was $0.8 \AA$ in combination with a $62 \mathrm{~mm} \times 62 \mathrm{~mm}$ CCD Bruker AXS SMART APEX detector of $60 \mu \mathrm{m}$ resolution. During the high-temperature measurement, an Oxford Cryosystems low-temperature device was used as a regulated hot air blower $( \pm 0.1 \mathrm{~K}$; range 80-400 K). Data treatment (integration, scaling) was performed with the APEX2 suite of programs (Bruker, 2014). Reflection patterns were in accordance with space group Pbnm for both the room temperature and $370 \mathrm{~K}$ structures. Experimental details of data collection and structure determination are summarized in Table 1. The programmes Jana2006 (Petříček et al., 2006) and SHELX (Sheldrick, 2008) were used for the single-crystal structure analyses. Refinements were based on $F^{2}$. All hydrogen atoms were found by differenceFourier syntheses for the room temperature (RT) data set. They were not restrained with HFIX commands, as the refinement process revealed plausible electron density for the hydrogen positions with reliable, though shortened, oxygenhydrogen distances. For the $370 \mathrm{~K}$ measurement the data quality did not allow us to find hydrogen positions or to refine the anisotropic displacement parameters for all the atoms. Isotropic factors were used for refinement instead. The displacement ellipsoids for the RT measurement are plausible.

Powder diffraction data were acquired using a Bruker D8 goniometer with a Paar XRK900 nonambient device, a copper X-ray tube $(40 \mathrm{kV}, 40 \mathrm{~mA})$ and Lynx-Eye position-sensitive detector. The measurements were from RT to $498 \mathrm{~K}$ in $5 \mathrm{~K}$ steps with $1 \mathrm{~s}$ per point and from $11-80^{\circ} 2 \theta$ using $0.01^{\circ} 2 \theta$ step widths. At $488 \mathrm{~K}$ an extended measurement with $2.5 \mathrm{~s}$ per step was performed for structure determination. The powder X-ray pattern at $488 \mathrm{~K}$ was refined with the Rietveld section of the program GSAS (Larson and Von Dreele, 1994; Rietveld, 1967) with the graphical user interface EXPGUI (Toby, 2001). For this purpose, a structure dataset with coordinates from a single-crystal refinement was modified and subsequently refined using the 
MARTIN ENDE ETAL.

TABLE 1. Crystal and experimental data of $\mathrm{PbAl}_{2}\left[(\mathrm{OH})_{2} \mid \mathrm{Si}_{2} \mathrm{O}_{7}\right] \cdot \mathrm{H}_{2} \mathrm{O}$.

\begin{tabular}{|c|c|c|c|}
\hline Parameter & $298 \mathrm{~K}$ & $370 \mathrm{~K}$ & $488 \mathrm{~K}$ \\
\hline$a(\AA)$ & $5.851(1)$ & $5.859(1)$ & $5.875(1)$ \\
\hline$b(\AA)$ & $9.028(2)$ & $9.048(1)$ & $9.017(1)$ \\
\hline$c(\AA)$ & $13.295(3)$ & $13.354(2)$ & $13.367(2)$ \\
\hline$V\left(\AA^{3}\right)$ & $702.3(2)$ & $707.9(2)$ & $708.1(2)$ \\
\hline Space group & Pbnm (no. 62) & Pbnm (no. 62) & Cmcm (no. 63) \\
\hline$D_{\text {calc }}\left(\mathrm{g} / \mathrm{cm}^{3}\right)^{*}$ & 4.553 & 4.517 & 4.516 \\
\hline$\mu\left(\mathrm{mm}^{-1}\right)^{*}$ & 24.54 & 29.32 & 51.61 \\
\hline Z & 4 & 4 & 4 \\
\hline Crystal size $(\mu \mathrm{m})$ & $15 \times 15 \times 6$ & $8 \times 5 \times 5$ & powder \\
\hline Diffractometer & Bruker APEX II & SCD ANKA/KIT & Bruker D8 \\
\hline Radiation & $0.71073 \AA(\mathrm{MoK} \alpha)$ & $0.8 \AA$ & $1.5418\left(\mathrm{CuK \alpha} \alpha_{1,2}\right)$ \\
\hline$\theta_{\min }-\theta_{\max }\left(^{\circ}\right)$ & $3.06-40.10$ & $3.43-31.31$ & $5.50-40.00$ \\
\hline No. of observed reflect. $[I>3 \sigma(I)]$ & 12,689 & 2638 & 132 \\
\hline No. of unique reflect. $[I>3 \sigma(I)]$ & 1435 & 673 & 132 \\
\hline No. of param. used in refinement & 80 & 37 & $20^{\mathrm{b}}$ \\
\hline$R_{\text {int }}$ & 0.071 & 0.152 & - \\
\hline$R_{1}(\%)$ & $3.3^{\mathrm{a}}$ & $6.0^{\mathrm{a}}$ & $7.3^{\mathrm{c}}$ \\
\hline$R_{\mathrm{w}}\left(R_{2}\right)(\%)$ & $5.2^{\mathrm{a}}$ & $13.0^{\mathrm{a}}$ & $9.8^{\mathrm{c}}$ \\
\hline Goof & $1.10^{\mathrm{a}}$ & $1.92^{\mathrm{a}}$ & $1.39^{\mathrm{c}}$ \\
\hline
\end{tabular}

*calculated for complete formula (including $\mathrm{H}_{2} \mathrm{O}$ and hydroxyl group).

${ }^{\mathrm{a}} R_{1}, R_{2}$ and Goof from Jana2006 (Petříček et al., 2006) using $F^{2}$ weighting; ${ }^{\mathrm{b}}$ plus background terms; ${ }^{\mathrm{c}} R_{\mathrm{p}}, R_{\mathrm{wp}}$ and Goof from GSAS (Larson and Von Dreele, 1994; Rietveld, 1967).

powder data. Restraints for $\mathrm{SiO}_{4}$ tetrahedra, using $\mathrm{Si}-\mathrm{O}$ and $\mathrm{O}-\mathrm{O}$ bond distances from the $370 \mathrm{~K}$ single-crystal refinement with a variation of $\pm 0.03 \AA$, were applied in order to obtain stable refinement. Selected crystal data and measurement details for the three different crystal structure refinements are summarized in Table 1.

\section{Results}

\section{Crystal growth}

The Pb-lawsonite crystals obtained by the piston cylinder experiments were transparent, clear, idiomorphic, mostly cube-shaped, but less commonly prismatic. However, the larger crystals show a pronounced prismatic shape with a maximum edge length of $20 \mu \mathrm{m}$ and an average size of $15 \mu \mathrm{m} \times$ $5 \mu \mathrm{m} \times 5 \mu \mathrm{m}$ (Fig. 2). There were no visible intergrowths. The crystallinity was proven to be sufficient with Raman spectroscopy as well as powder and single-crystal XRD. The purity of the synthesis batch was determined by powder XRD to be $\sim 98$ wt. $\%$. Traces of coesite and an unidentified hydrated $\mathrm{Pb}$ carbonate were observed as additional phases. The size of the grains of the $\mathrm{Pb}$-lawsonite matrix was $<3 \mu \mathrm{m}$.

\section{Raman spectroscopy}

Powder Raman spectra of $\mathrm{Pb}$-lawsonite at different temperatures are shown in Figs 3 and 4. While Fig. 4 shows the region between 40 and $1140 \mathrm{~cm}^{-1}$ with lattice vibrations, silicate and $\mathrm{AlO}_{6}$ stretching vibrations, Fig. 3 presents the range from 2300 to $4000 \mathrm{~cm}^{-1}$ where the stretching vibrations of the $\mathrm{H}_{2} \mathrm{O}$ molecule and the hydroxyl groups occur. In Fig. 4 it is obvious that an isolated group of bands between 780 and $1100 \mathrm{~cm}^{-1}$ (intense at $\sim 950 \mathrm{~cm}^{-1}$ ) is clearly separated from a fairly uniform group of bands ranging from 42 to $480 \mathrm{~cm}^{-1}$ and two bands at 553 and $667 \mathrm{~cm}^{-1}$. Each of the $\mathrm{SiO}_{4}$ tetrahedra in $\mathrm{Pb}$-lawsonite is connected via $\mathrm{O} 1$ into $\mathrm{Si}_{2} \mathrm{O}_{7}$ dimers and are fixed with the six terminal $\mathrm{O}$ atoms to the relatively rigid chains of $\mathrm{AlO}_{6}$ octahedra. Thus, the vibrational behaviour is different from isolated $\mathrm{SiO}_{4}$ tetrahedra. Referring to Le Cléac'h and Gillet (1990), stretching vibrations of the $\mathrm{Si}_{2} \mathrm{O}_{7}$ dimers generally occur at wavenumbers above $\sim 700 \mathrm{~cm}^{-1}$ (Lazarev, 1972; Farmer, 1974; Kieffer, 1979, 1980; Hofmeister et al., 1987) and can be divided into the stretching vibrations of $\mathrm{SiO}_{3}$ terminal units $\left(\sim 800-1000 \mathrm{~cm}^{-1}\right)$ and the symmetric $\left(\sim 600-700 \mathrm{~cm}^{-1}\right)$ and 

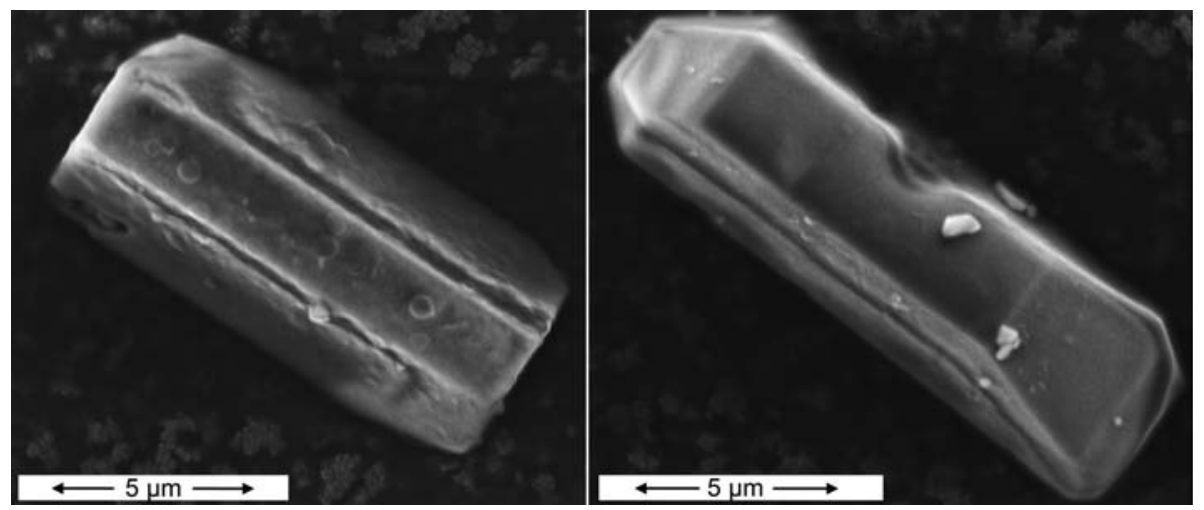

FIG. 2. Scanning electron microscopy - secondary electron images of two larger Pb-lawsonite crystals synthesized from $\mathrm{PbAl}_{2} \mathrm{SiO}_{\mathrm{x}(7-8)}$ glass and excess water in a piston cylinder experiment at $600^{\circ} \mathrm{C}$ and $4 \mathrm{GPa}$.

antisymmetric $\quad\left(\sim 1000-1200 \mathrm{~cm}^{-1}\right) \quad$ stretching vibration of the Si-O-Si bridge (Lazarev, 1972; Gabelica-Robert and Tarte, 1979). Following Le Cléac'h and Gillet (1990), in lawsonite these vibrations start with $v_{\mathrm{s}}-\mathrm{Si}-\mathrm{O}-\mathrm{Si}$ at $694 \mathrm{~cm}^{-1}$ accompanied by a group of $\mathrm{SiO}_{3}$ stretching vibrations with a maximum at $935 \mathrm{~cm}^{-1}$ and end with $v_{\text {as }}-\mathrm{Si}-\mathrm{O}-\mathrm{Si}$ at $1047 \mathrm{~cm}^{-1}$. In Pb-lawsonite the band pattern appears very similar to that of lawsonite at RT. One stronger band is observed at $667 \mathrm{~cm}^{-1}\left(v_{\mathrm{s}}-\mathrm{Si}-\mathrm{O}-\mathrm{Si}\right)$ followed by a group with a maximum at $943 \mathrm{~cm}^{-1}\left(\mathrm{SiO}_{3}\right.$ stretching vibrations). The terminal band is at $1077 \mathrm{~cm}^{-1}\left(v_{\mathrm{as}}-\mathrm{Si}-\mathrm{O}-\mathrm{Si}\right)$. Table 2 shows the band assignments of $\mathrm{Pb}$ lawsonite, proposed by analogy with those of lawsonite (Le Cléac'h and Gillet, 1990). The stretching vibrations of the $\mathrm{H}_{2} \mathrm{O}$ molecule and the hydroxyl groups between 3150 and $3350 \mathrm{~cm}^{-1}$ (RT) show a large temperature-induced shift. In particular, the band at $3329 \mathrm{~cm}^{-1}$ (RT) exhibits a positive shift of $>150 \mathrm{~cm}^{-1}$ between $83 \mathrm{~K}$ and $573 \mathrm{~K}$ (Fig. 3). A weak band at $858 \mathrm{~cm}^{-1}$ (RT) also shows a significant shift from $877 \mathrm{~cm}^{-1}$ at $83 \mathrm{~K}$ to $799 \mathrm{~cm}^{-1}$ at $573 \mathrm{~K}$. The temperature-dependent band shifts reveal the same non-uniform changes for the band at $3329 \mathrm{~cm}^{-1}$ (RT) as for the band at $858 \mathrm{~cm}^{-1}$ (RT) (Fig. 5).

Further detailed investigations were made with the band around $858 \mathrm{~cm}^{-1}$, starting at room temperature and going up to $\sim 650 \mathrm{~K}$ with $5 \mathrm{~K}$ steps (Fig. 5). This band is relatively broad and comparable to a band in lawsonite at $809 \mathrm{~cm}^{-1}$. Most probably it is not related to $\mathrm{SiO}_{3}$ stretching vibrations (Libowitzky and Rossman, 1996), but

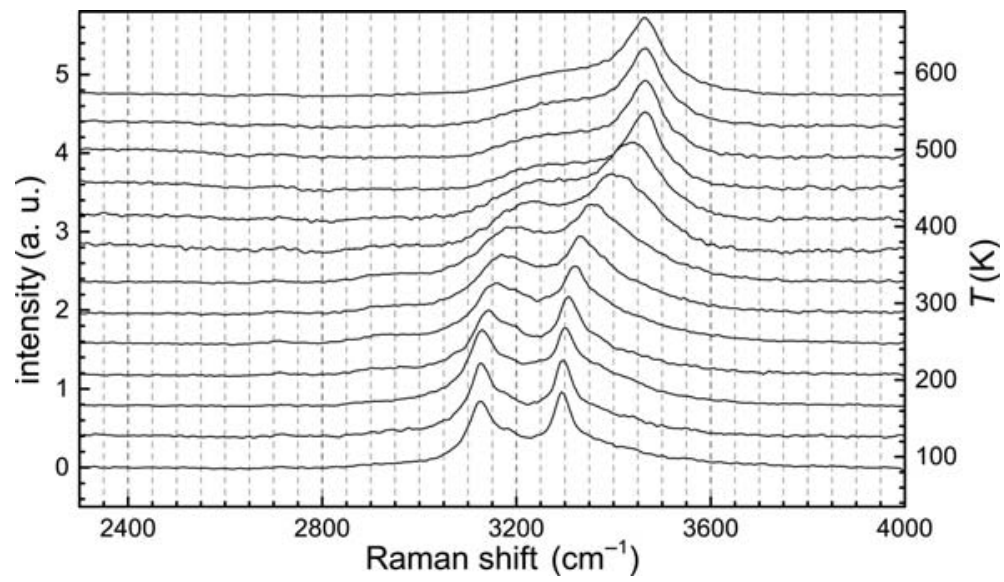

Fig. 3. Temperature-dependent Raman spectra of Pb-lawsonite from 83 to $573 \mathrm{~K}$ showing stretching vibrations of the hydroxyl groups and the $\mathrm{H}_{2} \mathrm{O}$ molecule. Spectra are vertically offset and smoothed only for presentation. 


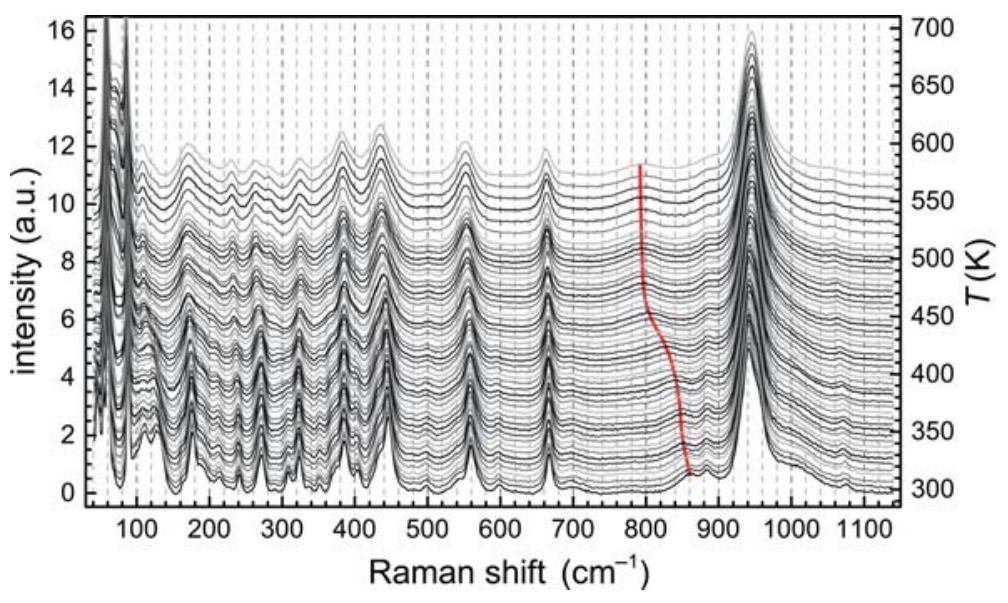

FIG. 4. Temperature-dependent Raman spectra of Pb-lawsonite from 298 to $573 \mathrm{~K}$ showing the vibrations of the $\mathrm{Si}_{2} \mathrm{O}_{7}$ groups and $\mathrm{AlO}_{6}$ octahedra as well as lattice vibrations. Spectra are vertically offset. The bold line at $\approx 790-860 \mathrm{~cm}^{-1}$ indicates the maximum of the $\gamma-\mathrm{OH}$ vibrational band.

rather arises from out-of-plane bending of a hydroxyl group, i.e. a so-called $\gamma-\mathrm{OH}$ vibration (Novak, 1974). Two clear non-uniform changes in the band shift are obvious around 355 and $445 \mathrm{~K}$ (Fig. 5). A principal component analysis was applied using the full spectra, including band positions and intensities, to confirm the significance of the band shifts. Subsequent hierarchical clustering, which joins similar observations and successively connects the next similar observations

TABLE 2. Raman band assignment for Pb-lawsonite and lawsonite (Le Cléac'h and Gillet, 1990) at room temperature. Band positions are reported in wavenumbers (Raman shift).

\begin{tabular}{lcc}
\hline $\begin{array}{l}\text { Band position } \mathrm{Pb}- \\
\text { lawsonite }\end{array}$ & $\begin{array}{c}\text { Band } \\
\text { assignment }\end{array}$ & $\begin{array}{c}\text { Band position } \\
\text { lawsonite }\end{array}$ \\
\hline 446 & $\delta / \gamma-\mathrm{Si}-\mathrm{O}-\mathrm{Si}$ & $455^{\mathrm{a}}$ \\
561 & $\delta-\mathrm{SiO}_{3}$ & $562^{\mathrm{a}}$ \\
667 & $v_{\mathrm{s}}-\mathrm{Si}-\mathrm{O}-\mathrm{Si}$ & 694 \\
858 & $\gamma-\mathrm{OH}$ & $809^{\mathrm{b}}$ \\
$885-1012$, & $\mathrm{v}-\mathrm{SiO} 3$ & $912-963$, \\
943 max. & & 935 max. \\
1077 & $v_{\mathrm{as}}-\mathrm{Si}-\mathrm{O}-\mathrm{Si}$ & 1047 \\
1349 & $\delta-\mathrm{OH}$ & - \\
1489 & $\delta-\mathrm{H}_{2} \mathrm{O}$ & 1578 \\
c. $3150-3350$ & $v-\mathrm{H}_{2} \mathrm{O} / \mathrm{OH}$ & c. $2960-3580^{\mathrm{c}}$ \\
& & \\
\hline
\end{tabular}

${ }^{\mathrm{a}}$ Not assigned; ${ }^{\mathrm{b}}$ assumed as $\mathrm{AlO}_{6}$ stretching vibration; ${ }^{\mathrm{c}}$ from IR study (Libowitzky and Rossman, 1996). to these, was calculated with squared Euclidean distances. For the PCA a preceding scree test/plot (Cattel, 1966) was carried out to check the optimum usable factors, which represent the principal part of the variance. Instead of a correlation matrix, a covariance matrix was used. To prevent interaction with the Rayleigh line filter only the region from 75 to $1200 \mathrm{~cm}^{-1}$ was taken into account for the analyses. The scree plot limited the meaningful selection of principal components to two or three. The first two principal components include $94.6 \%$ of the total variance of the original data and the subsequent Euclidean hierarchical cluster analysis shows plausible results, splitting the non-ambient data points into four meaningful groups (Fig. 6). These are separated by the temperatures of $353 / 358$, $443 / 448$ and $498 / 503 \mathrm{~K}$. Both, the first and the second transition points are in good agreement with the band fitting method described above. A three times longer measuring time possibly causes the outlier at $298 \mathrm{~K}$. The points in group 5 above $503 \mathrm{~K}$ may be split off due to the onset of dehydration. Raman spectroscopic measurements were also carried out from RT to $83 \mathrm{~K}$. These data reveal no indication of any further non-uniform change or discontinuity.

\section{Single-crystal $X$-ray diffraction}

The crystal structure of $\mathrm{Pb}$-lawsonite at room temperature, space group $\mathrm{Pbnm}$, first derived from powder X-ray data by Dörsam et al. (2011), was confirmed (Tables 1 and 3). Estimates for the 


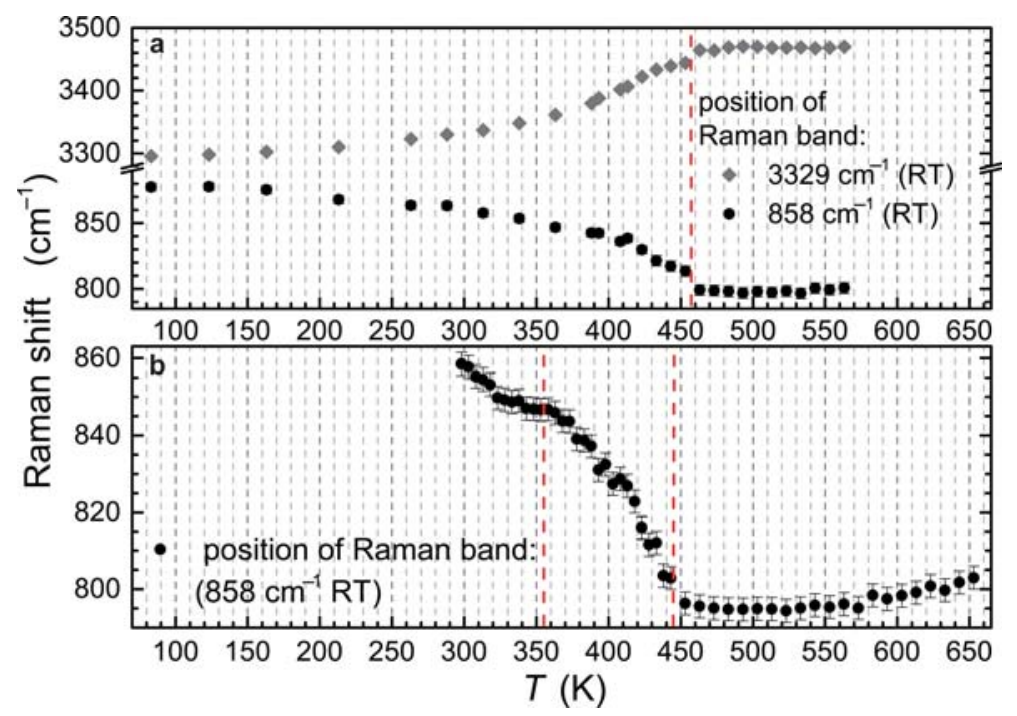

FIG. 5. Band shift analysis of two Raman bands. The band at $858 \mathrm{~cm}^{-1}$ (RT) is assigned to an out-of-plane bending vibration of the hydroxyl group and the band at $3329 \mathrm{~cm}^{-1}$ to a stretching vibration of the $\mathrm{OH}$ group. The lower plot shows two, clear, non-uniform changes, one around $355 \mathrm{~K}$ and the other around $445 \mathrm{~K}$. The temperature behaviour of $(a)$ and $(b)$ is slightly different, possibly caused by the use of a single crystal $(a)$ and Pb-lawsonite powder $(b)$ for analysis.

hydrogen positions and anisotropic displacement parameters are presented in Tables 3 and 4 . With a size of $\sim 10 \mu \mathrm{m}$ the crystal was very small and the $R_{\text {int }}$ value of $7.1 \%$ was relatively high. Nevertheless, a good fit was obtained (Table 1). The $R_{\text {int }}$ value of the $370 \mathrm{~K}$ synchrotron data was $13.0 \%$. However, the crystal volume was $6-7$ times smaller than the former (c.f. Table 1). The fits were calculated using Jana2006 (Petříček et al., 2006) and the integrated $F^{2}$ weighting. Refined atomic positions and displacement parameters for the single-crystal refinement are summarized in Table 5. Because of the small crystallite size of the $370 \mathrm{~K}$ sample only isotropic displacement parameters were refined, but these had to be manually fixed to 0.001 for $\mathrm{Si}$ and $\mathrm{Al}$ to gain a

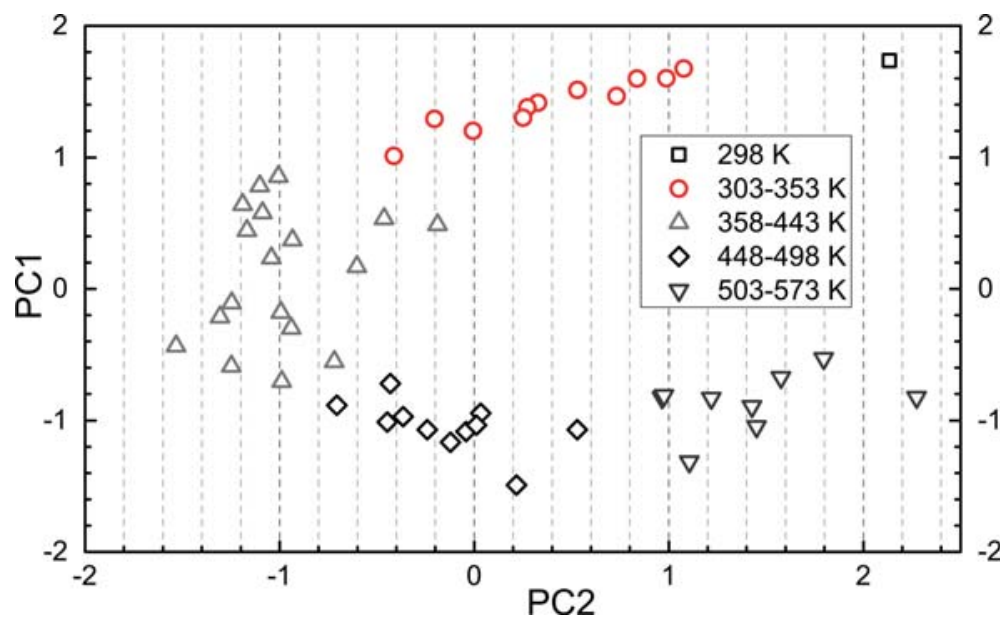

Fig. 6. Results of the principal component analysis with subsequent Euclidean hierarchical cluster analysis of the Raman spectra of Pb-lawsonite at different temperatures. 
TABLE 3. Refined fractional atomic coordinates and equivalent anisotropic displacement parameters of orthorhombic $\mathrm{Pb}$-lawsonite at room temperature (space group setting Pbnm).

\begin{tabular}{lcllll}
\hline Atom & Wyck. & \multicolumn{1}{c}{$x$} & \multicolumn{1}{c}{$y$} & \multicolumn{1}{c}{$z$} & $100 \cdot U_{\mathrm{eq}}^{*}\left(\AA^{2}\right)$ \\
\hline $\mathrm{Pb}$ & 4c & $0.02342(30)$ & $0.16182(20)$ & 0.25 & $0.95(6)$ \\
$\mathrm{Si}$ & $8 \mathrm{~d}$ & $0.51116(16)$ & $0.01394(12)$ & $0.37034(80)$ & $0.44(2)$ \\
$\mathrm{Al}$ & $8 \mathrm{~d}$ & $0.23638(18)$ & $0.75543(13)$ & $0.00238(90)$ & $0.43(2)$ \\
$\mathrm{O} 1$ & 4c & $0.53360(60)$ & $0.97730(40)$ & 0.25 & $0.77(7)$ \\
$\mathrm{O} 2$ & 8d & $0.74220(50)$ & $0.10030(30)$ & $0.40110(20)$ & $0.65(5)$ \\
$\mathrm{O3}$ & 8d & $0.49280(40)$ & $0.85190(30)$ & $0.42680(20)$ & $0.58(5)$ \\
$\mathrm{O} 4 \mathrm{~h}$ & 8d & $0.02130(40)$ & $0.15210(30)$ & $0.55690(20)$ & $0.64(5)$ \\
O5w & 4c & $0.06840(90)$ & $0.87930(60)$ & 0.25 & $1.65(9)$ \\
$\mathrm{O6}$ & $8 \mathrm{~d}$ & $0.28720(40)$ & $0.11420(30)$ & $0.39170(20)$ & $0.68(5)$ \\
$\mathrm{Hw}$ & 8d & $0.012(9)$ & $0.842(8)$ & $0.203(7)$ & $5.00^{* *}$ \\
$\mathrm{Hh}$ & 8d & $0.040(8)$ & $0.068(6)$ & $0.556(4)$ & $0.80^{* *}$ \\
\end{tabular}

Hydrogen and oxygen atoms of the $\mathrm{H}_{2} \mathrm{O}$ and hydroxyl groups are characterized with a ' $w$ ', i.e. Hw, $\mathrm{O} 5 \mathrm{w}$ and an 'h', i.e. $\mathrm{O} 4 \mathrm{~h}, \mathrm{Hh}$.

${ }^{*} U_{\text {eq }}=\left(U^{11} U^{22} U^{33}\right)^{1 / 3} ; * * U_{\text {iso }}$.

stable fit. For $\mathrm{Pb}$, anisotropic displacement parameters were refined and converged to $U^{11}=$ $0.0055(4), U^{22}=0.0028(5), U^{33}=0.0091(4)$ and $U^{13}=0.0023(3) \AA^{2}$, which are all reasonable, though smaller than at RT. All tested specimens at 298 and $370 \mathrm{~K}$ exhibit more than one diffracting domain in the single-crystal XRD pattern, as evidenced by extra diffraction peaks. However, non-merohedral twinning could not be confirmed. No apparent differences between the crystal structures of $\mathrm{Pb}$-lawsonite at 298 and $370 \mathrm{~K}$ were found; a possible explanation for the non-uniform change of the Raman and X-ray data around $355 \mathrm{~K}$ is given below.

\section{Powder X-ray diffraction}

The space group suggested by using the PANalytical X'pert software HighScore at $488 \mathrm{~K}$ was $\mathrm{Cmcm}$ and thus corresponds to one of the minimal non-isomorphic supergroups of space group Pbnm (Pnma). Moreover, it is identical to that of the room-temperature structure of lawsonite. To compare the unit-cell dimensions and the atom positions directly with the $\mathrm{Cmcm}$ setting of $\mathrm{Pb}$ lawsonite at $488 \mathrm{~K}$ the non-standard space group setting Pbnm was used instead of Pnma for the lower-temperature phases. Thus, $\mathrm{Pb}$-lawsonite in space group Pbnm is obtained by a 'klassengleiche'

TABLE 4. Anisotropic displacement parameters (x100) of orthorhombic Pb-lawsonite at room temperature (space group setting Pbnm).

\begin{tabular}{llllccc}
\hline & $U^{11}\left(\AA^{2}\right)$ & $U^{22}\left(\AA^{2}\right)$ & $U^{33}\left(\AA^{2}\right)$ & $U^{12}\left(\AA^{2}\right)$ & $U^{13}\left(\AA^{2}\right)$ & $U^{23}\left(\AA^{2}\right)$ \\
\hline $\mathrm{Pb}$ & $0.976(9)$ & $0.933(9)$ & $0.946(10)$ & $0.132(8)$ & 0 & 0 \\
$\mathrm{Si}$ & $0.51(4)$ & $0.47(4)$ & $0.34(4)$ & $0.03(3)$ & $-0.03(3)$ & $0.03(3)$ \\
$\mathrm{Al}$ & $0.43(5)$ & $0.44(4)$ & $0.41(5)$ & $0.04(4)$ & $-0.07(4)$ & $0.00(4)$ \\
$\mathrm{O} 1$ & $1.07(15)$ & $0.74(16)$ & $0.49(18)$ & $0.32(14)$ & 0 & 0 \\
$\mathrm{O} 2$ & $0.80(10)$ & $0.45(11)$ & $0.78(13)$ & $0.01(9)$ & $0.10(10)$ & $-0.30(10)$ \\
$\mathrm{O} 3$ & $0.75(11)$ & $0.38(10)$ & $0.60(12)$ & $-0.10(8)$ & $-0.07(8)$ & $0.11(9)$ \\
O4h & $0.93(11)$ & $0.26(10)$ & $0.73(13)$ & $0.01(10)$ & $0.02(9)$ & $0.19(9)$ \\
O5w & $2.40(20)$ & $1.80(20)$ & $0.80(20)$ & $-0.57(18)$ & 0 & 0 \\
O6 & $0.61(11)$ & $0.61(11)$ & $0.76(14)$ & $0.11(9)$ & $-0.13(9)$ & $-0.08(10)$
\end{tabular}


TABLE 5. Refined fractional atomic coordinates and isotropic displacement parameters of orthorhombic $\mathrm{Pb}$-lawsonite at $370 \mathrm{~K}$ (space group setting Pbnm).

\begin{tabular}{lccccl}
\hline Atom & Wyckoff & \multicolumn{1}{c}{$x$} & \multicolumn{1}{c}{$y$} & \multicolumn{1}{c}{$z$} & $100 \cdot U_{\text {iso }}\left(\AA^{2}\right)$ \\
\hline $\mathrm{Pb}$ & $4 \mathrm{c}$ & $0.02130(11)$ & $0.16171(9)$ & 0.25 & $0.58(2)^{\mathrm{a}}$ \\
$\mathrm{Si}$ & $8 \mathrm{~d}$ & $0.5106(5)$ & $0.0135(4)$ & $0.3701(3)$ & $0.1^{\mathrm{b}}$ \\
$\mathrm{Al}$ & $8 \mathrm{~d}$ & $0.2381(6)$ & $0.7549(5)$ & $0.0021(3)$ & $0.1^{\mathrm{b}}$ \\
$\mathrm{O} 1$ & $4 \mathrm{c}$ & $0.5291(18)$ & $0.9766(14)$ & 0.25 & $0.3(3)$ \\
$\mathrm{O} 2$ & $8 \mathrm{~d}$ & $0.7417(14)$ & $0.1008(11)$ & $0.3998(7)$ & $0.7(2)$ \\
$\mathrm{O} 3$ & $8 \mathrm{~d}$ & $0.4932(11)$ & $0.8523(10)$ & $0.4269(7)$ & $0.11(18)$ \\
$\mathrm{O} 4 \mathrm{~h}$ & $8 \mathrm{~d}$ & $0.0198(12)$ & $0.1509(10)$ & $0.5573(8)$ & $0.33(18)$ \\
O5w & $4 \mathrm{c}$ & $0.063(2)$ & $0.8797(18)$ & 0.25 & $1.0(4)$ \\
$\mathrm{O} 6$ & $8 \mathrm{~d}$ & $0.2869(14)$ & $0.1133(11)$ & $0.3914(7)$ & $0.5(2)$ \\
\hline
\end{tabular}

${ }^{\mathrm{a}} U_{\text {eq }}=\left(U^{11} U^{22} U^{33}\right)^{1 / 3},{ }^{\mathrm{b}}$ fixed value.

symmetry reduction of index two $(\mathrm{k} 2)$ from the Cmcm high-temperature space group (Hahn, 2005; Wondraschek and Müller, 2010). Regarding only the type of symmetry relationship, this is a similar $\mathrm{k} 2$ reduction as for lawsonite $(\mathrm{Cmcm}-\mathrm{Pmcn})$ at $273 \mathrm{~K}$ (Libowitzky and Armbruster, 1995) and hennomartinite $(\mathrm{Cmcm}-\mathrm{Pmcn})$ at $423 \mathrm{~K}$ (Libowitzky and Armbruster, 1996). However, it has different directions of symmetry reduction and a different role of $\mathrm{H}$ atoms (see below). Analyses of the powder patterns measured in $5 \mathrm{~K}$ steps from RT up to $498 \mathrm{~K}$ confirm the phase transition of $\mathrm{Pb}$ lawsonite from Pbnm to Cmcm. The (101), (103), (121) and (212) diffraction peaks, forbidden by the extinction rule for $C$ centring, can only be observed at lower temperatures in the primitive space group, are progressively weaker above $350 \mathrm{~K}$ and are absent above $450 \mathrm{~K}$ (arrows in Fig. 7). In contrast, the (110) peak, which has nearly the same intensity at RT as the (101) peak and fulfils the reflection condition of space group $\mathrm{Cmcm}$, is constantly present, even above $450 \mathrm{~K}$ (Fig. 7).

Again, for a first overview, a PCA with subsequent hierarchical cluster analysis was made from the powder XRD data by using a covariance matrix. A prefixed scree plot (Cattel, 1966) limited the meaningful selection of principal components to two or three. As the first two components represent more than $88.6 \%$ of the total variance of the original data, and as the cluster analysis showed distinct results, the choice of three principal components was disregarded. The clustering of

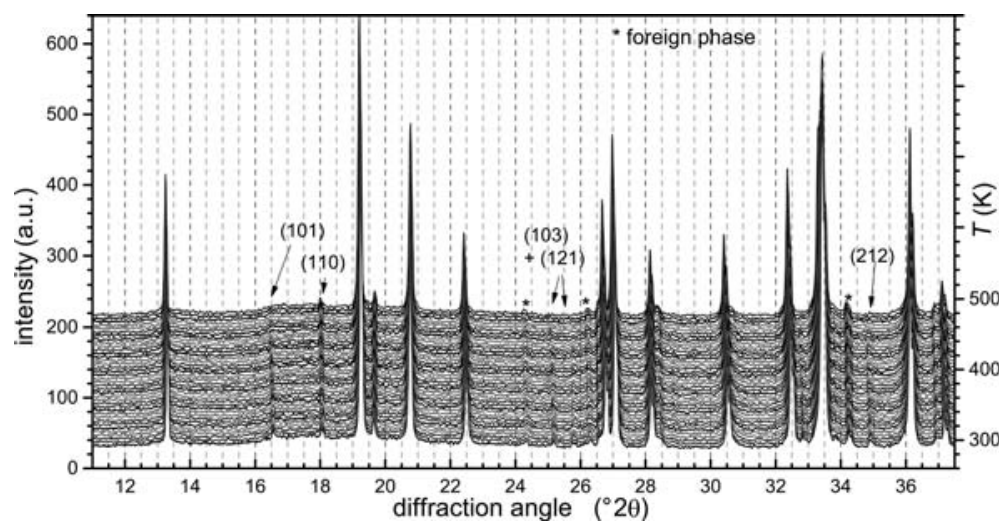

Fig. 7. Powder XRD patterns of $\mathrm{Pb}$-lawsonite ( $T=298$ to $498 \mathrm{~K}$ ) showing the phase transition from space group Pbnm to $\mathrm{Cmcm}$ around $450 \mathrm{~K}$. The XRD patterns were smoothed and vertically offset to enhance the visibility of the small diffraction peaks. Arrows indicate a number of weak, critical reflections and their indices. 


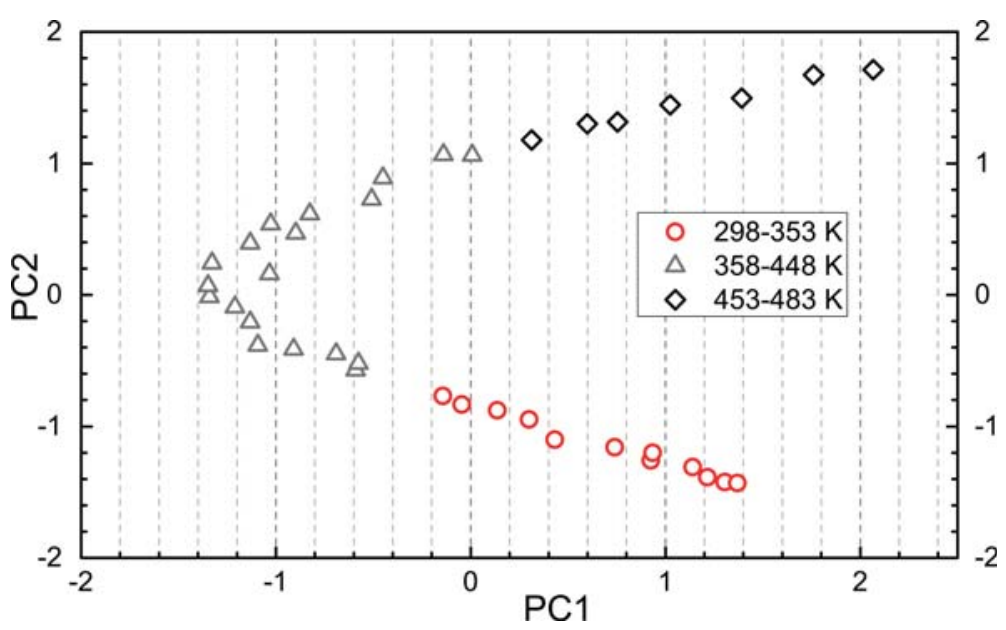

FIG. 8. Results from a principal component analysis with subsequent hierarchical cluster analysis of the temperaturedependent $\mathrm{Pb}$-lawsonite powder X-ray pattern data.

each two points, which was seen in a previous analysis and which was due to the mechanical shift, carried out for compensation of the thermal expansion of the sample holder, was reduced by a mathematical correction of the displacement shifts causing a higher noise in the present PCA analysis. The PCA analysis (Fig. 8) now shows a smooth change in the diffraction data between the determined transition points and a distinct jump from 353 to $358 \mathrm{~K}$. The hierarchical cluster analysis reveals three groups, which are separated at 353 $358 \mathrm{~K}$ and $448-453 \mathrm{~K}$ and thus indicates nearly the same transition temperatures as obtained with Raman spectroscopy.

At first glance, the lattice parameters, which were obtained by LeBail refinements (LeBail, 1988) of the diffraction patterns using TOPAS (Coelho, 2007), did not show this behaviour. Nevertheless, knowledge of the possible transition points enabled a good fit of an exponential decay function $\left(\mathrm{A} \cdot \exp ^{(\mathrm{x} / \mathrm{t})}+\mathrm{y}_{0}\right)$ to the data points between them (Fig. 9). The deviation, $\Delta$, from this function yields two clear, non-uniform changes around 355 and $445 \mathrm{~K}$ for the lattice parameters $a$ and $c$ and at least one for $b$ around $450 \mathrm{~K}$ (Fig. 9).

\section{Discussion}

\section{Structural changes in Pb-lawsonite}

The structural transitions of lawsonite with changing temperature, discovered initially by Libowitzky and Armbruster (1995), have been studied in great detail and found to be quite complex (Meyer et al., 2001; Carpenter et al., 2003; Sondergeld et al., 2005; Carpenter, 2006; Salje and Carpenter, 2011; Salje et al., 2011; Pavlov, 2013). Combining the results of an earlier study of phase transitions of hennomartinite (Sr$\mathrm{Mn}^{3+}$-lawsonite; Libowitzky and Armbruster, 1996) and the present paper, it becomes clear that incorporation of larger cations such as $\mathrm{Sr}^{2+}$ and $\mathrm{Pb}^{2+}$ in $\mathrm{Ca}^{2+}$ sites leads to a shift of phase transitions to higher temperatures (lawsonite $\mathrm{T}_{\mathrm{C}} \approx 150,273 \mathrm{~K}$; hennomartinite $\mathrm{T}_{\mathrm{C}} \approx 368,423 \mathrm{~K}$; Pb-lawsonite $\mathrm{T}_{\mathrm{C}} \approx 355,445 \mathrm{~K}$ ). However, with a different space-group evolution in the present case it is necessary to consider different structural transition behaviour. It is obvious that the phase transition of $\mathrm{Pb}$-lawsonite around $445 \mathrm{~K}$ is related to a change of space group from $\mathrm{Pbnm}$ to $\mathrm{Cmcm}$. To gain the relative and absolute atom displacements for every atom during the transitions the software COMPSTRU (Tasci et al., 2012) was applied to the fractional atom coordinates of Tables 3,5 and 6. At first this program searches for a transformation that best matches the lattice parameters of both structures to be compared. A structure transformation is achieved by determining the best pairing of the atom positions of the two structures using a suitable Euclidean normalizer. The results of this atom displacement analysis are plotted in Fig. 10.

A comparison of the structure at 370 and $488 \mathrm{~K}$ reveals a maximum displacement of the atom positions of $\mathrm{O} 5 \mathrm{w}(\approx 0.40 \AA)$ followed by $\mathrm{O} 1(\approx$ $0.2 \AA)$, both in the a direction. Atoms $\mathrm{O} 2$ and $\mathrm{O} 6$, 

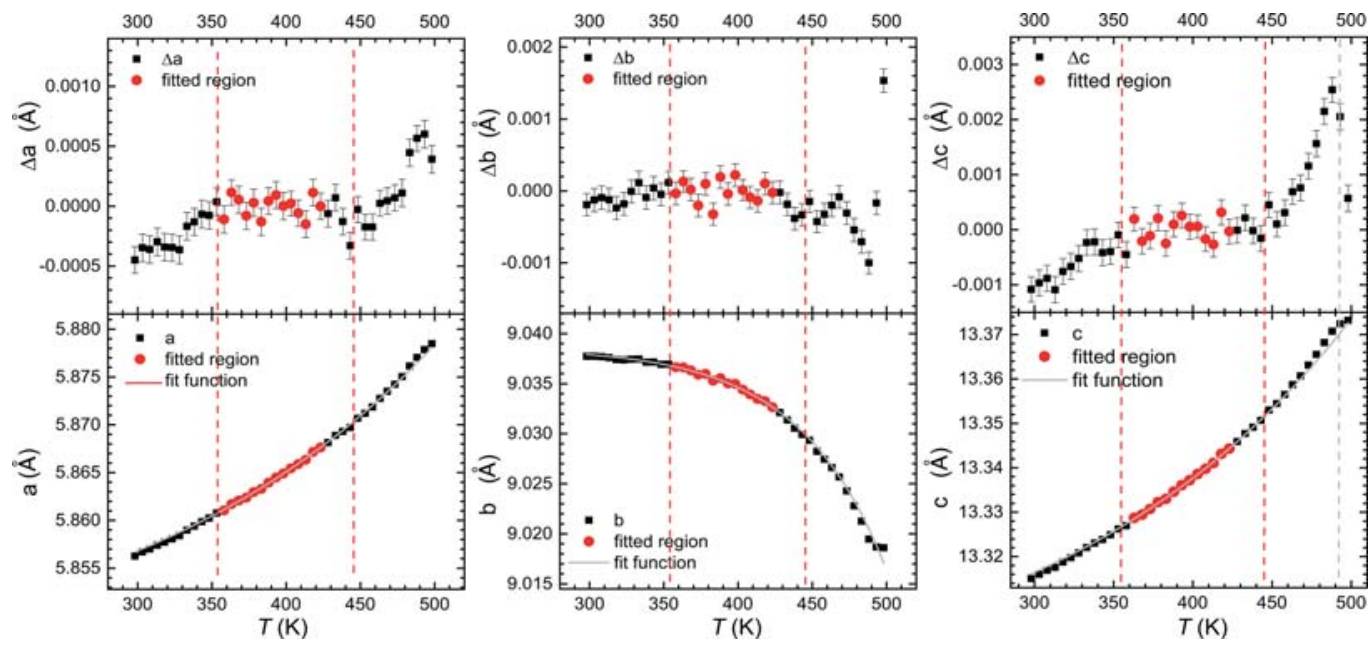

FIG. 9. Lattice parameters $a, b, c$ versus temperature. The lower plots show the original parameters and an exponential decay function fitted to the central (marked) data points. The upper plots show the differences between the fit functions and the data points. The dashed lines mark the transition temperatures that were obtained from the principal component analysis plus subsequent cluster analysis of the diffraction patterns.

which are part of the $\mathrm{AlO}_{6}$ octahedron and are merged into the same crystallographic position for the $488 \mathrm{~K}$ structure, show a total displacement $(\mathrm{u}=$ $\mathrm{u}_{x}+\mathrm{u}_{y}+\mathrm{u}_{z}$ ) of $\sim 0.12$ and $0.13 \AA$, respectively. O4h of the hydroxyl group shows a u value of $\sim 0.14 \AA$ A. However, hydrogen atom displacements cannot be determined by X-ray data alone. The mentioned shift of O1, the bridging atom in the silicate dimer, is accompanied by a small variation of the $\mathrm{Si}-\mathrm{O} 1-\mathrm{Si}$ angle $\left(154.90(5)^{\circ}\right.$ for $298 \mathrm{~K}$; $155.31(20)^{\circ}$ for $370 \mathrm{~K} ; 154.02(21)^{\circ}$ for $\left.488 \mathrm{~K}\right)$. It should be noted that the $\mathrm{Si}-\mathrm{O} 1-\mathrm{Si}$ angle of the $488 \mathrm{~K}$ structure refinement is biased by a high uncertainty caused by the use of powder XRD data. In the powder diffraction analysis the $\mathrm{Si}-\mathrm{O}$ and $\mathrm{O}-$ $\mathrm{O}$ distances had to be restrained and refined with fixed isotropic displacement parameters. Nevertheless, the temperature-induced change of this angle is supported by an analysis of the band position of the Raman mode around $446 \mathrm{~cm}^{-1}$ (RT) in Fig. 11. In their study of hemimorphite, which has similar $\mathrm{Si}_{2} \mathrm{O}_{7}$ dimers as lawsonite but no $\mathrm{AlO}_{6}$ octahedra, Frost et al. (2007) assign a band at $451 \mathrm{~cm}^{-1}$ to an $\mathrm{Si}-\mathrm{O}-\mathrm{Si}$ out-of-plane bending vibration. Consequently, the band at $446 \mathrm{~cm}^{-1}$ (RT) in Pb-lawsonite could also result from

TABLE 6. Refined fractional atomic coordinates of orthorhombic Pb-lawsonite at $488 \mathrm{~K}$ (space-group setting $\mathrm{Cmcm}$ ). The isotropic displacement parameters in the powder diffraction measurements are those of the $370 \mathrm{~K}$ refinement.

\begin{tabular}{lclll}
\hline Atom & Wyckoff & \multicolumn{1}{c}{$x$} & \multicolumn{1}{c}{$y$} \\
\hline $\mathrm{Pb}$ & $4 \mathrm{c}$ & 0.5 & $0.16102(14)$ & 0.25 \\
$\mathrm{Si}$ & $8 \mathrm{f}$ & 0 & $0.01252(50)$ & $0.13094(31)$ \\
$\mathrm{Al}$ & $8 \mathrm{~d}$ & 0.25 & 0.25 & 0 \\
$\mathrm{O} 1$ & $4 \mathrm{c}$ & 0 & $0.0282(15)$ & 0.75 \\
$\mathrm{O} 2$ & $16 \mathrm{~h}$ & $0.2281(11)$ & $0.10712(65)$ & $0.10479(36)$ \\
$\mathrm{O} 3$ & $8 \mathrm{f}$ & 0 & $-0.1463(12)$ & $0.07258(48)$ \\
$\mathrm{O} 4 \mathrm{~h}$ & $8 \mathrm{f}$ & 0 & $0.3476(13)$ & $0.05224(48)$ \\
O5w & $4 \mathrm{c}$ & 0 & $0.3759(15)$ & 0.25
\end{tabular}




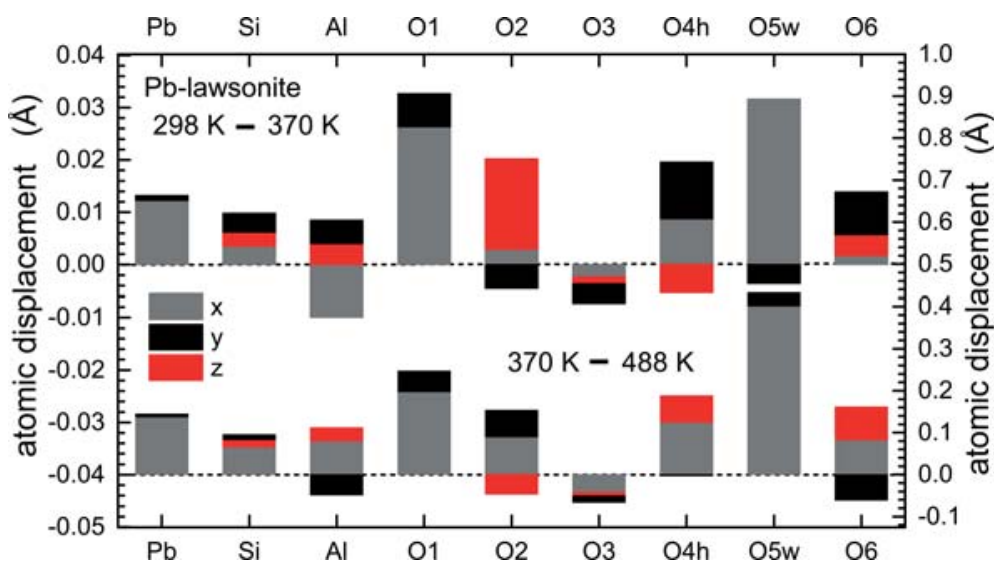

FIG. 10. Changes in positional parameters of Pb-lawsonite from room temperature (space group Pbnm - upper bars) to $370 \mathrm{~K}(\mathrm{Pbnm})$ to $488 \mathrm{~K}$ ( $\mathrm{Cmcm}$ - lower bars).

bending/out-of-plane bending vibrations of $\mathrm{Si}-\mathrm{O}-$ $\mathrm{Si}$. Moreover, during the $445 \mathrm{~K}$ transition the $446 \mathrm{~cm}^{-1}$ band shows nearly the same behaviour as the $\gamma-\mathrm{OH}$ vibration at $\sim 858 \mathrm{~cm}^{-1}$ (Figs 5 and 11), which is the most strongly shifted Raman band $<1100 \mathrm{~cm}^{-1}$. This implies that the $\mathrm{Si}-\mathrm{O}-\mathrm{Si}$ bending/ out-of-plane bending vibration is considerably affected by the transition around $445 \mathrm{~K}$ and also by the phenomenon around $355 \mathrm{~K}$ (Fig. 11). These in turn are related to the change of the bridging $\mathrm{Si}-\mathrm{O}-\mathrm{Si}$ angle between the $\mathrm{SiO}_{4}$ tetrahedra, accompanied by merging/separation of the $\mathrm{O} 2 / \mathrm{O} 6$ atoms linking $\mathrm{SiO}_{4}$ and $\mathrm{AlO}_{6}$ polyhedra. The positive slope of the excess $c$ lattice parameter versus temperature (after background subtraction) below $355 \mathrm{~K}$ and above $445 \mathrm{~K}$ (Fig. 9) seems to be a further consequence of the less straightened $\mathrm{Si}-\mathrm{O}-\mathrm{Si}$ angle and therefore has the same origin. So far, the structural transition of $\mathrm{Pb}$-lawsonite around $445 \mathrm{~K}$ can be considered as a predominantly displacive phase transition of the rather rigid mixed polyhedral framework probably not

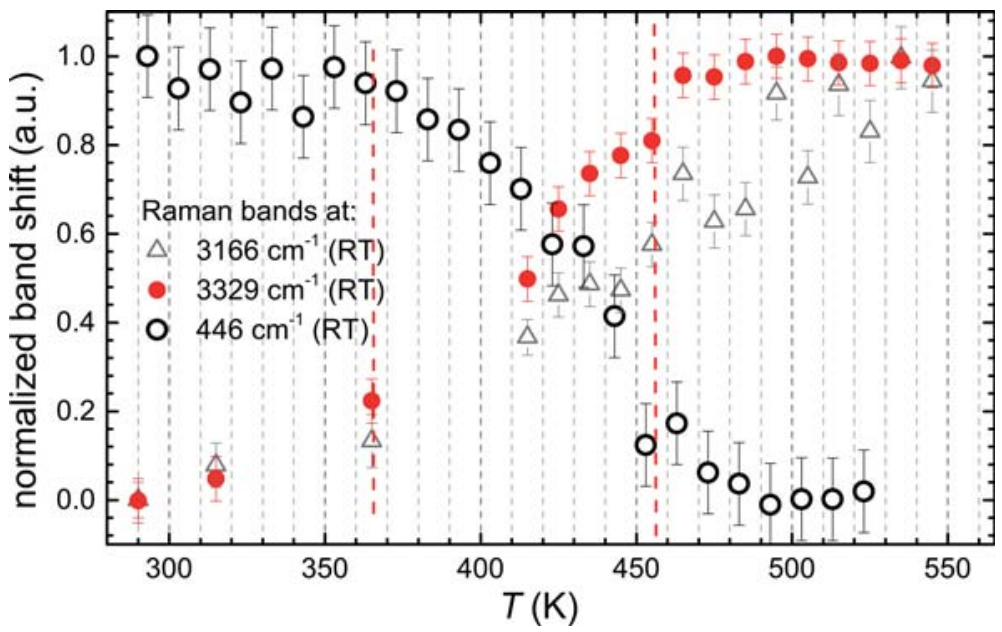

FIG. 11. Excess Raman band position of the $\delta / \gamma-\mathrm{Si}-\mathrm{O}-\mathrm{Si}$ band at $446 \mathrm{~cm}^{-1}$ (RT). The non-uniform change around $355 \mathrm{~K}$ is not obvious at first sight, but the $445 \mathrm{~K}$ transition is well defined. Also visible is the temperature-induced evolution of the Raman shift of the hydroxyl-group stretching vibration at $3329 \mathrm{~cm}^{-1}$ (RT) vs. the band at $3166 \mathrm{~cm}^{-1}$ (RT), probably belonging to a stretching vibration of the $\mathrm{H}_{2} \mathrm{O}$ molecule. Temperatures are slightly higher compared with the other Raman data, possibly caused by the use of a single crystal. 
involving proton ordering/disordering processes. The latter can only be inferred from the strong nonuniform change of the $\mathrm{OH}^{-}$stretching band at $3329 \mathrm{~cm}^{-1}$ (Fig. 5), caused by accompanying changes of $\mathrm{H}$ bonds. Structural changes around $355 \mathrm{~K}$ are generally weaker by an order of magnitude than those at the $445 \mathrm{~K}$ transition (Fig. 10). This is further supported by the small changes in the data curves in Figs 3, 4, 5, 7, 9, 10 and 11. The strongest atom displacement between 298 and $370 \mathrm{~K}$ is revealed by the $\mathrm{O} 5 \mathrm{w}$ atom $\left(\mathrm{u}_{x}>\right.$ $0.03 \AA$ ) of the $\mathrm{H}_{2} \mathrm{O}$ molecule (Fig. 10). This is followed by the shifts of $\mathrm{O} 1 \quad\left(\mathrm{u}_{x}<0.03 \AA\right), \mathrm{O} 2$ $\left(\mathrm{u}_{z} \approx 0.02 \AA\right)$ and $\mathrm{O} 4 \mathrm{~h} \quad\left(\mathrm{u}_{y}\right.$ and $\left.\mathrm{u}_{x} \approx 0.01 \AA\right)$ oxygen atoms. Thus, for the non-uniform changes around $355 \mathrm{~K}$, the trend of atom displacement is roughly the same as for the $445 \mathrm{~K}$ transition, even if the magnitude is smaller.

\section{Band assignments and suggestions from Raman spectroscopy}

In the Raman data, some similarities between lawsonite and $\mathrm{Pb}$-lawsonite are observed. As the $\mathrm{H}_{2} \mathrm{O}$ molecule has a dipole moment and no centre of symmetry, all possible vibrations occur in Raman and IR spectra. If the data of Libowitzky and Rossman (1996) are compared with Figs 3 and 4 of the present work, it becomes obvious that $\mathrm{Pb}$ lawsonite Raman spectra at RT are similar to lawsonite IR spectra at RT, presuming the highenergy bands of lawsonite around 3550 and $3612 \mathrm{~cm}^{-1}$ are ignored. Moreover, in lawsonite an increase of temperature causes the bands at 3245 and $2960 \mathrm{~cm}^{-1}$ (RT) to shift considerably to higher wavenumbers. Analogous behaviour is observed for the bands around $3329 \mathrm{~cm}^{-1}$ and $3166 /$ $3210 \mathrm{~cm}^{-1}$ (RT) in Pb-lawsonite. Table 7 compares $\mathrm{O}-\mathrm{O}$ bond distances of the $\mathrm{O} 4 \mathrm{~h}, \mathrm{O} 2$ and $\mathrm{O} 5 \mathrm{w}$ oxygen atoms for the structure refinements of $\mathrm{Pb}$ lawsonite at different temperatures. According to the correlation of stretching frequency and $\mathrm{H}$-bond distances (Libowitzky, 1999) the change of the $\mathrm{O} 4 \mathrm{~h} \cdots \mathrm{O} 2$ hydrogen-bond distances from $2.73 \AA$ (RT) to $2.92 \AA(488 \mathrm{~K})$ in Pb-lawsonite is expected to cause a theoretical band shift from $\sim 3250$ to $3500 \mathrm{~cm}^{-1}$. Figure 3 shows the band at $3329 \mathrm{~cm}^{-1}$ (RT) shifting to $3468 \mathrm{~cm}^{-1}$ at $488 \mathrm{~K}$. Therefore, we assign the $\mathrm{Pb}$-lawsonite Raman band at $3329 \mathrm{~cm}^{-1}$ (RT) to a hydroxyl stretching vibration. The change of the distances is within error for the non-uniform change around $355 \mathrm{~K}$, but becomes obvious for the $445 \mathrm{~K}$ transition (Table 7). The $\mathrm{O} 4 \mathrm{~h} \cdots \mathrm{O} 2$ distance
TABLE 7. Hydrogen-bond distances $[\AA]$ in $\mathrm{Pb}-$ lawsonite.

\begin{tabular}{cccc}
\hline & $\mathrm{d}(\mathrm{O} 4 \mathrm{~h} \cdots \mathrm{O} 2)$ & $\mathrm{d}(\mathrm{O} 4 \mathrm{~h} \cdots \mathrm{O} 4 \mathrm{~h})$ & $\mathrm{d}(\mathrm{O} 5 \mathrm{w} \cdots \mathrm{O} 4 \mathrm{~h})$ \\
\hline $298 \mathrm{~K}$ & $2.725(4)$ & $3.149(4)$ & $2.635(3)$ \\
$370 \mathrm{~K}$ & $2.733(13)$ & $3.139(13)$ & $2.633(11)$ \\
$488 \mathrm{~K}$ & $2.919(11)$ & $3.083(15)$ & $2.656(7)$
\end{tabular}

in $\mathrm{Pb}$-lawsonite $(2.73 \AA$ at $\mathrm{RT})$ is considerably shorter than the $\mathrm{O} 4 \mathrm{~h} \cdots \mathrm{O} 4 \mathrm{~h}$ distance (3.15 $\AA$ at RT) even at $488 \mathrm{~K}(2.92 \AA$ vs. $3.08 \AA)$ and it is slightly shorter than the $\mathrm{O} 4 \mathrm{~h} \cdots \mathrm{O} 4 \mathrm{~h}$ distance in lawsonite $(2.75 \AA)$. These distance constraints between potential donor and acceptor $\mathrm{O}$ atoms could be the reason for the different orientation of the hydrogen bonds of the $\mathrm{OH}$ groups in lawsonite versus $\mathrm{Pb}$-lawsonite. The correlation between hydrogen-bond distances and wavenumbers of O-H stretching modes (Libowitzky, 1999) is used for the prediction of a stretching vibration of the $\mathrm{H}_{2} \mathrm{O}$ molecule as well. The bond distances at $\mathrm{RT}$ are 1.95(9) $\AA$ for $\mathrm{d}\left(\mathrm{Hw}^{\cdots}{ }^{\cdots} \mathrm{O} 4 \mathrm{~h}\right)$ [overestimated due to a too short O5-Hw distance] and 2.635(3) $\AA$ for $\mathrm{d}$ (O5w $\cdots$ O4h) [underestimated due to the bent geometry of $\left.\mathrm{O} 5-\mathrm{Hw}^{\cdots} \mathrm{O} 4 \mathrm{~h}\right]$; this suggests wavenumbers of $\sim 3380$ and $2950 \mathrm{~cm}^{-1}$ and thus an averaged value of $3165 \mathrm{~cm}^{-1}$. Figure 3 shows two bands at $3166 \mathrm{~cm}^{-1}$ and $3210 \mathrm{~cm}^{-1}$ (RT). The former seems to have different behaviour for the temperature evolution compared to the hydroxyl stretching vibration $\left(3329 \mathrm{~cm}^{-1}\right.$; Fig. 11) and different behaviour in comparison to the $\gamma-\mathrm{OH}$ vibration at $858 \mathrm{~cm}^{-1}$.

Compared to lawsonite, the $\mathrm{Cmcm}$ space-group symmetry of $\mathrm{Pb}$-lawsonite should result in only one hydroxyl stretching band and two closely spaced (symmetric and antisymmetric) stretching bands of the $\mathrm{H}_{2} \mathrm{O}$ molecule. Thus, we consider the two bands at $\sim 3200 \mathrm{~cm}^{-1}$ to belong to the $\mathrm{H}_{2} \mathrm{O}$ stretching vibrations and the band at a higher wavenumbers to $\mathrm{OH}$ stretching. In Table 8, the assignments of the strongest $\mathrm{O}-\mathrm{H}$ stretching vibrations for $\mathrm{Pb}-$ lawsonite are listed and compared to lawsonite. The $\mathrm{Cmcm}$ structure of lawsonite should result in a similar Raman/IR spectrum to that of hightemperature $\mathrm{Cmcm} \mathrm{Pb}$-lawsonite. However, as indicated by numerous previous investigations, the $\mathrm{H}_{2} \mathrm{O}$ and $\mathrm{OH}$ groups are dynamically disordered in lawsonite. The single $\mathrm{H}$ sites are close to those of the low-temperature Pmcn structure (Libowitzky and Rossman, 1996; Kozlova and Gabuda, 2013). 
TABLE 8. Assignment of the strongest $\mathrm{O}-\mathrm{H}$ stretching vibrations of $\mathrm{Pb}$-lawsonite compared to lawsonite (Libowitzky and Rossman, 1996) at RT.

\begin{tabular}{lcc}
\hline $\begin{array}{l}\text { Raman band position } \\
\text { Pb-lawsonite }\left(\mathrm{cm}^{-1}\right)\end{array}$ & $\begin{array}{c}\text { Band } \\
\text { assignment }\end{array}$ & $\begin{array}{c}\text { IR band position } \\
\text { lawsonite }\left(\mathrm{cm}^{-1}\right)\end{array}$ \\
\hline- & $\mathrm{v}-\mathrm{H}_{2} \mathrm{O}^{\mathrm{a}}$ & 3612 \\
- & $\mathrm{v}-\mathrm{OH}^{\mathrm{a}}$ & 3550 \\
3329 & $\mathrm{v}-\mathrm{OH}$ & 3245 \\
3210 & $\mathrm{v}_{3}-\mathrm{H}_{2} \mathrm{O}$ & 2960 \\
3166 & $\mathrm{v}_{1}-\mathrm{H}_{2} \mathrm{O}$ & \\
& & \\
\hline
\end{tabular}

${ }^{\text {a }}$ caused by disordered hydrous species.

Thus it results in two high-energy stretching modes (no or weak $\mathrm{H}$ bonding) and two low-energy modes (strong $\mathrm{H}$ bonding) in the Raman spectra. As there is no high-energy Raman band in $\mathrm{Pb}$-lawsonite, in either Pbnm or in $\mathrm{Cmcm}$, this phase seems to lack disordered hydrous species with additional weak $\mathrm{H}$ bonds and therewith an oscillation of the $\mathrm{H}_{2} \mathrm{O}$ molecule between two equivalent sites. Distances between the $\mathrm{H}_{2} \mathrm{O}$ oxygen $(\mathrm{O} 5 \mathrm{w})$ and the $\mathrm{H}$-bond acceptor $(\mathrm{O} 4 \mathrm{~h})$ do not change remarkably during the phase transitions $(2.636(3)-2.633(11)-2.656(7) \AA$, Table 7). There is no need for the $\mathrm{H}_{2} \mathrm{O}$ molecule and the $\mathrm{OH}$ groups to order/disorder as implied by the missing disordered hydrogen sub-lattice. It seems that the hydrogen atoms of the $\mathrm{H}_{2} \mathrm{O}$ molecules oppose the $445 \mathrm{~K}$ transition by enhancing hydrogen bonds, and this could cause the non-uniform changes in Raman band shifts around $355 \mathrm{~K}$. Furthermore, the non-uniform change in Fig. 11 around $355 \mathrm{~K}$ is more distinct for the vibrational mode at $3166 \mathrm{~cm}^{-1}\left(v_{1}\right.$ of $\left.\mathrm{H}_{2} \mathrm{O}\right)$ than for the $3329 \mathrm{~cm}^{-1}$ band $(v$ of $\mathrm{OH})$. Nevertheless, the phase transition in hennomartinite $\left(\mathrm{SrMn}_{2}\left[(\mathrm{OH})_{2} \mid\right.\right.$ $\left.\mathrm{Si}_{2} \mathrm{O}_{7}\right] \cdot \mathrm{H}_{2} \mathrm{O}$ ), which is also of the lawsonite type and which has a similar rigid framework to lawsonite (Libowitzky and Armbruster, 1996), provides another potential explanation. In the low-temperature structure $\left(P 2_{1} \mathrm{Cn}\right)$ of hennomartinite, twinning parallel to (100) was found and it was assumed that the ordering of $\mathrm{H}_{2} \mathrm{O}$ and $\mathrm{OH}$ groups does not occur in the same way within the entire crystal, but rather ranges from local disorder to extensive twin domains (Libowitzky and Armbruster, 1996). This phenomenon could hold for $\mathrm{Pb}$-lawsonite as well. In particular, the anisotropic displacement parameters of the RT structure of $\mathrm{Pb}$-lawsonite, especially with respect to $\mathrm{O} 5 \mathrm{w}$
$\left(U^{11} \approx 0.024(2), U^{22} \approx 0.018(2) \rightarrow U_{\mathrm{eq}} \approx 0.017(1) \AA\right)$ compared with the value of the $370 \mathrm{~K}$ structure $\left(U_{\text {iso }} \approx 0.010(4) \AA\right)$ supports this hypothesis. These stronger displacements at lower temperature could be a hint for such a domain development due to local disorder. However, instead of twinning a strong intergrowth of the $\mathrm{Pb}$-lawsonite crystals was found in the single-crystal $\mathrm{X}$-ray measurements at 298 and $370 \mathrm{~K}$. This effect is caused by parallel growth of adjacent crystals, and no twinning was involved. In addition, the anisotropic displacement parameters of hennomartinite show different behaviour (Libowitzky and Armbruster, 1996).

\section{Comparison of lawsonite and Pb-lawsonite transitions}

Libowitzky and Armbruster (1995) and Sondergeld et al. (2005) found that the coordinates of the framework atoms remain quite unchanged during the two temperature-induced phase transitions of lawsonite. Thus the transition of $\mathrm{Pb}$-lawsonite around $445 \mathrm{~K}$ is different from that of lawsonite at $273 \mathrm{~K}$ due to an obvious contribution of framework distortions in Pb-lawsonite and the loss of a different mirror plane, i.e. in Pb-lawsonite the mirror plane ' $m$..' is lost, in lawsonite at $<273 \mathrm{~K}$ it is the mirror plane '...m'. Consequently, the Wyckoff positions in $\mathrm{Pb}$-lawsonite and lawsonite below the higher-temperature phase transition are quite different. In both phases, the oxygen atom $\mathrm{O} 2$ splits from $16 h$ to two $8 d$ positions $(\mathrm{O} 2+\mathrm{O} 6)$. For the $445 \mathrm{~K}$ transition of $\mathrm{Pb}$-lawsonite there is no further split, whereas in lawsonite for the $273 \mathrm{~K}$ transition all the $8 f$ positions split to two $4 c$ positions. This applies to $\mathrm{Si}, \mathrm{Al}, \mathrm{O} 4 \mathrm{~h}, \mathrm{O} 3$ as well as the hydrogen atoms of the hydroxyl group and $\mathrm{H}_{2} \mathrm{O}$ molecule. The different behaviour of $\mathrm{Pb}$ lawsonite during the phase transition compared to lawsonite is probably due to a widening of the structure channel, which consists of $\mathrm{AlO}_{6}$ octahedral chains and $\mathrm{Si}_{2} \mathrm{O}_{7}$ dimers. This channel hosts the $\mathrm{Pb}^{2+}$ cation $\left(\mathrm{Ca}^{2+}\right.$ in lawsonite) and the $\mathrm{H}_{2} \mathrm{O}$ molecule. Comparing the $\mathrm{Cmcm}$ structures of lawsonite and $\mathrm{Pb}$-lawsonite, the straighter $\mathrm{Si}-\mathrm{O}-$ $\mathrm{Si}$ angle $\left(154^{\circ}\right.$ vs. $137^{\circ}$, Fig. 12) in Pb-lawsonite provides more space for the cation. This results in 12-fold coordination of the $\mathrm{Pb}$ ion, because six more remote atoms $(\mathrm{O} 3$ and the next but one $\mathrm{O} 1$ and $\mathrm{O} 5$ atoms) are shifted towards the $\mathrm{Pb}$ ion and six closer $\mathrm{O}$ atoms drift away, compared to distances in lawsonite (Fig. 13). With regard to Shannon (1976) the $\mathrm{Pb}^{2+}$ cation has a large $1.49 \AA$ 

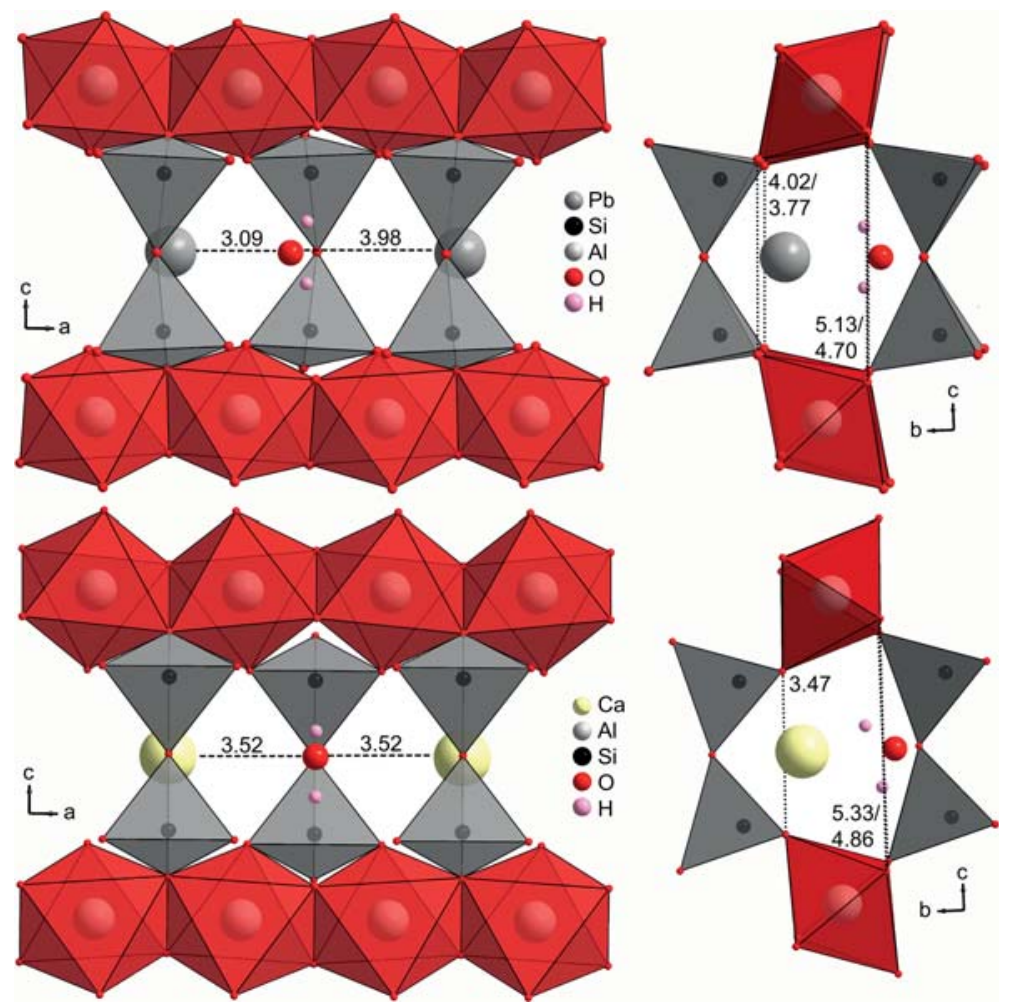

Fig. 12. Comparison of the structural channels of lawsonite (Pmcn, $233 \mathrm{~K})$ and Pb-lawsonite (Pbnm, $298 \mathrm{~K})$ hosting the $\mathrm{Ca} / \mathrm{Pb}$ cation and the $\mathrm{H}_{2} \mathrm{O}$ molecule, in two different orientations. Numbers denote the interatomic distances in $\AA$. Note the straightened $\mathrm{Si}-\mathrm{O}-\mathrm{Si}$ angle in $\mathrm{Pb}$-lawsonite, resulting in a more circular cross-section of the channel.

theoretical effective ionic radius in ideal 12 -fold coordination. This is much larger compared with an effective ionic radius of $1.00 \AA$ for $\mathrm{C}^{2+}$ cation in ideal six-fold coordination. It could be that the $\mathrm{O} 2$ and $\mathrm{Pb}$ atoms come too close to each other below $445 \mathrm{~K}$. Whatever the reason, the $\mathrm{Pb}$ atom is moved slightly out of its position and the $\mathrm{O} 2$ position is split into $\mathrm{O} 2+\mathrm{O} 6$ (Fig. 13). As a consequence the ' $m$..' mirror plane is lost, but the '...m' mirror plane, which is lost in lawsonite around $273 \mathrm{~K}$, is preserved. In addition, the distance of $3.52 \AA$ between $\mathrm{Pb}$ and the next nearest neighbour $\mathrm{O} 5 \mathrm{w}$ drops to $3.09 \AA$, while the other $\mathrm{O} 5 \mathrm{w}$ atom distance increases to $3.98 \AA$. Thus the $\mathrm{H}_{2} \mathrm{O}$ molecule is pulled out of the ' $m$.'. mirror plane as well. The same happens with the next-nearest neighbour $\mathrm{O} 1$ atoms, but the shift is not as pronounced as for the $\mathrm{O} 5 \mathrm{w}$ distances (Fig. 13). These shifts result in an irregular ten-fold coordination of the $\mathrm{Pb}^{2+}$ cation (Fig. 13). As a consequence, the theoretical effective ionic radius of the $\mathrm{Pb}^{2+}$ cation falls to $1.40 \AA$. If the $\mathrm{Pb}-\mathrm{O} 1$ bond of $3.42 \AA$ is included in the $\mathrm{Pb}$ coordination (resulting in $\mathrm{Pb}^{[11]}$ ) the theoretical effective ionic radius would fall to $1.45 \AA$. Dörsam et al. (2011) assumed a possible higher coordination of $\mathrm{Pb}$ compared to the six-fold coordination of $\mathrm{Ca}$ in the RT structure of lawsonite, but they only included the $\mathrm{O} 3$ atoms in the coordination sphere, and ignored the $\mathrm{O} 5 \mathrm{w}$ and $\mathrm{O} 1$ atoms.

The abovementioned widening of the framework channel on one side $(\mathrm{O} 2 \cdots \mathrm{O} 2, \mathrm{O} 6 \cdots \mathrm{O} 6)$ leads to a shrinkage on the other side $(\mathrm{O} 3 \cdots \mathrm{O} 3, \mathrm{O} 4 \mathrm{~h} \cdots \mathrm{O} 4 \mathrm{~h}$; Fig. 12). This shrinkage is the reason for the different behaviour of the $\mathrm{H}_{2} \mathrm{O}$ molecule of $\mathrm{Pb}$ lawsonite compared to lawsonite. Viewed along the $a$ axis, the $\mathrm{H}_{2} \mathrm{O}$ molecule is located opposite the cation, though at a different 'height', in the framework channel (Fig. 12). On this side, the channel is shrunk, i.e. Pb-lawsonite has shorter distances between $\mathrm{O} 3 \cdots \mathrm{O} 3 \quad(4.70 \AA)$ and $\mathrm{O} 4 \mathrm{~h} \cdots \mathrm{O} 4 \mathrm{~h}(5.13 \AA)$ than those in lawsonite 


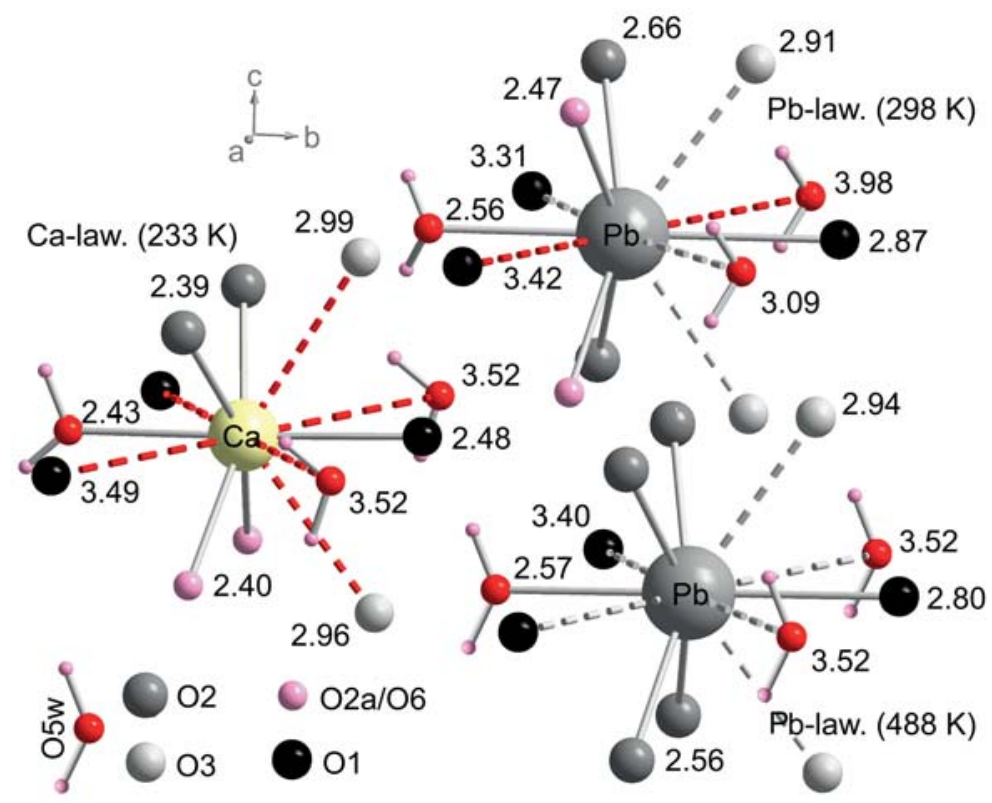

FIG. 13. Coordination around $\mathrm{Ca}$ and $\mathrm{Pb}$ in lawsonite and $\mathrm{Pb}$-lawsonite. Dashed lines in grey show possible coordination bonds, while dashed lines in red show probably broken or absent bonds. Numbers denote bond lengths in $\AA$.

(4.86 and $5.33 \AA$; Fig. 12). In lawsonite below $273 \mathrm{~K}$ the $\mathrm{H}_{2} \mathrm{O}$ molecule cannot be stabilized in the centre between the attractive forces of the remote $\mathrm{H}$ bond acceptors $\mathrm{O} 4 \mathrm{~h}$ and $\mathrm{O} 4 \mathrm{~h}$. Thus it makes one short $(\mathrm{Hw} \cdots \mathrm{O} 4 \mathrm{~h}: 1.79 \AA$, Hw-O5w: $0.87 \AA$; respectively $\mathrm{Hw}^{\cdots} \mathrm{O} 4 \mathrm{~h}: 1.70 \AA$ with restrained Hw-O5w: $0.98 \AA$ ) and one long hydrogen bond (Hwa ${ }^{\cdots}$ O4ha: $2.27 \AA$, Hwa-O5w: $0.78 \AA$; respectively Hwa' ${ }^{\circ}$ O4ha: $2.22 \AA$ with restrained Hwa-O5w: $0.98 \AA$ ), which breaks the '..m' mirror plane (Libowitzky and Armbruster, 1995; Libowitzky and Rossman, 1996). At room temperature, the $\mathrm{H}_{2} \mathrm{O}$ molecule in lawsonite oscillates between two equivalent sites similar to the ordered $\mathrm{H}$ positions below the phase transition at $273 \mathrm{~K}$. The refined distance between Hwa ${ }^{\cdots} \mathrm{O} 4 \mathrm{~h}$ is then $1.99 \AA$ (Hwa-O5w: $0.80 \AA$ ) and with a restrained Hw-O5w distance of $0.98 \AA$ it is $1.90 \AA$.

Due to comparably shortened $\mathrm{Hw}^{\cdots \cdot} \mathrm{O} 5 \mathrm{w}$ distances, the unrestrained values of lawsonite from Libowitzky and Armbruster (1995) can be better compared with the data of $\mathrm{Pb}$-lawsonite refined here. The distance of $\mathrm{Hw}^{\cdots} \mathrm{O} 4 \mathrm{~h}$ gained for $\mathrm{Pb}$ lawsonite is $1.95 \AA$. The difference between $1.95 \AA$ and $1.99 \AA$ is not large, but in lawsonite, the value is distorted (to lower values) by the oscillation effect. Consequently, the apparent $\mathrm{H}-$ $\mathrm{O}-\mathrm{H}$ angle of the $\mathrm{H}_{2} \mathrm{O}$ molecule in lawsonite at room temperature is $112.7^{\circ}$ and thus unreasonably large. In Pb-lawsonite at room temperature, the angle of $105.9^{\circ}$ almost matches the natural $104.5^{\circ}$ angle of a free-water molecule (Császár et al., 2005). Thus the average distance between $\mathrm{Hw}^{*} \mathrm{O} 4 \mathrm{~h}$ in the $\mathrm{Cmcm}$ structure of lawsonite is probably in the region of the average of the Pmcn structure of lawsonite $(1.79 \AA+2.27 \AA \approx 2.03 \AA)$, which is a minimum value as the $\mathrm{H}_{2} \mathrm{O}$ molecule has an angle of $107.6^{\circ}$. This small decrease of $\approx 0.1 \AA$ from $2.03 \AA$ in lawsonite to $1.95 \AA$ in Pb-lawsonite has the effect that the $\mathrm{H}_{2} \mathrm{O}$ molecule can be stabilized in the centre between the two H-bond acceptors. Thus the $\mathrm{H}_{2} \mathrm{O}$ molecule does not seem to make one short and one long hydrogen bond resulting in the break of the '..m' mirror plane as in lawsonite (Fig. 12). Hydrogen bond behaviour could be also the reason for the phenomenon around $355 \mathrm{~K}$, where the Raman shifts and lattice parameters versus temperature have a non-uniform change in slope. Indeed, below $445 \mathrm{~K}$ the $\mathrm{O} 5 \mathrm{w}$ oxygen atom is pulled off the mirror plane 'm..'. Nevertheless, the Hw hydrogen atoms do not shift much due to slightly shortened hydrogen bonding with O4h (Table 7). Thus, the $\mathrm{H}_{2} \mathrm{O}$ molecule is rather tilted than shifted from the (100) plane at $x=0$. This has no further effect slightly below $445 \mathrm{~K}$, but with decreasing temperature and increasing shift of $\mathrm{O} 5 \mathrm{w}$ accompanied by 
increasing tilting of the $\mathrm{H}_{2} \mathrm{O}$ molecule, the enhanced hydrogen bonds begin to stop the atom shifts. This is supported by the strongest shifting Raman band, which probably arises from $\gamma-\mathrm{OH}$ vibrations $\left(858 \mathrm{~cm}^{-1} \mathrm{RT}\right)$. It shows a similar strong wavenumber shift below and above $355 \mathrm{~K}$, but in the region of $40 \mathrm{~K}$ around this temperature, it is relatively stable (Fig. 5, lower plot). The same constant behaviour applies for the $\mathrm{Si}-\mathrm{O}-\mathrm{Si}$ angle, the Raman shift of the $\delta / \gamma-\mathrm{Si}-\mathrm{O}-\mathrm{Si}$ band and the $c$ lattice parameter (Figs 9 , 11). This temperature range with stabilized atom coordinates is probably caused by the hydrogen bonds, which are directed against the shift of $\mathrm{O} 5 \mathrm{w}$ caused by its interaction with the $\mathrm{Pb}^{2+}$ cation. It is concluded that the interaction of the large $\mathrm{Pb}^{2+}$ cation with the tight framework of $\mathrm{AlO}_{6}$ octahedra and $\mathrm{Si}_{2} \mathrm{O}_{7}$ dimers causes the structural transition around $445 \mathrm{~K}$ in $\mathrm{Pb}$-lawsonite, where the coordination number of $\mathrm{Pb}^{2+}$ is reduced from 12 to 10 or 11 . A transition due to proton ordering/disordering as was found for the phase transitions of lawsonite (Libowitzky and Armbruster, 1995; Libowitzky and Rossman, 1996) is not suggested, even though the hydrogen bonds have a great impact on the behaviour of the phase transition in $\mathrm{Pb}$-lawsonite.

\section{Acknowledgements}

This work was supported by FWF grant P23108-N19. The authors are grateful for the opportunity to use the synchrotron single-crystal diffraction beam line of ANKA/KIT in Karlsruhe, Germany. Hans-Peter Nahbein (GFZ, Potsdam) is thanked for measuring X-ray diffraction powder patterns of very small samples. They appreciate the hints and comments given by referees Ross Angel and Günther Redhammer as well as the associate editor Mark Welch.

\section{References}

Armbruster, T., Oberhänsli, R., Bermanec, V. and Dixon, R. (1993) Hennomartinite and kornite, two new $\mathrm{Mn}^{3+}$ rich silicates from the Wessels Mine, Kalahari, South Africa. Schweizerische Mineralogische und Petrographische Mitteilungen, 73, 349-355.

Brovarone, A.V. and Beyssac, O. (2014) Lawsonite metasomatism: a new route for water to the deep Earth. Earth and Planetary Science Letters, 393, 275-284.

Carpenter, M.A. (2006) Elastic properties of minerals and the influence of phase transitions. American Mineralogist, 91, 229-246.

Carpenter, M.A., Meyer, H.W., Sondergeld, P., Marion, S. and Knight, K.S. (2003) Spontaneous strain variations through the low temperature phase transitions of deuterated lawsonite. American Mineralogist, 88, 534-546.

Cattell, R.B. (1966) The scree test for the number of factors. Multivariate Behavioural Research, 1, 245-276.

Coelho, A.A. (2007) TOPAS academic version 4.1. Coelho software, Brisbane, Australia.

Császár, A.G., Czakó, G., Furtenbacher, T., Tennyson, J., Szalay, V., Shirin, S.V., Zobov, N.F. and Polyansky, O. L. (2005) On equilibrium structures of the water molecule. Journal of Chemical Physics, 122, 214305.

Daniel, L., Fiquet, G., Gillet, P., Schmidt, M.W. and Hanfland, M. (1999) P-V-T equation of state of lawsonite. Physics and Chemistry of Minerals, 26, 406-414.

Dörsam, G., Liebscher, A., Wunder, B., Franz, G. and Gottschalk, M. (2011) Synthesis of Pb-zoisite and Pblawsonite. Neues Jahrbuch für Mineralogie Abhandlungen, 188, 99-110.

Farmer, V.C. (1974) The Infrared Spectra of Minerals. Mineralogical Society, London.

Frost, R.L., Bouzaid, J.M. and Reddy, B.J. (2007) Vibrational spectroscopy of the sorosilicate mineral hemimorphite $\mathrm{Zn}_{4}(\mathrm{OH})_{2} \mathrm{Si}_{2} \mathrm{O}_{7} \cdot \mathrm{H}_{2} \mathrm{O}$. Polyhedron, 26, 2405-2412.

Gabelica-Robert, M. and Tarte, P. (1979) Synthesis, X-ray diffraction and vibrational study of silicates and germanates isostructural with kentrolite $\mathrm{Pb}_{2} \mathrm{Mn}_{2} \mathrm{Si}_{2} \mathrm{O}_{9}$. Journal of Solid State Chemistry, 27, 179-190.

Hahn, T. (2005) International Tables for Crystallography Volume A: Space-group Symmetry. Corrected reprint of the fifth edition, Wiley, New York.

Hofmeister, A.M., Hoering, T.C. and Virgo, D. (1987) Vibrational spectroscopy of beryllium aluminosilicates: heat capacity calculations from band assignments. Physics and Chemistry of Minerals, 14, 205-224.

Kawachi, Y. and Coombs, D.S. (1996) Noélbensonite, a new BaMn silicate of the lawsonite structure type, from Woods mine, New South Wales, Australia. Mineralogical Magazine, 60, 369-374.

Kieffer, S.W. (1979) Thermodynamics and lattice vibrations of minerals: 3. Lattice dynamics and an approximation for minerals with application to simple substances and framework silicates. Reviews of Geophysics and Space Physics, 17, 35-59.

Kieffer, S.W. (1980) Thermodynamics and lattice vibrations of minerals: 4. Application to chain and sheet silicates and orthosilicates. Reviews of Geophysics and Space Physics, 18, 862-886.

Kozlova, S.G. and Gabuda, S.P. (2013) Single-crystal ${ }^{1} \mathrm{H}$ NMR data and hydrogen atom disorder in lawsonite, $\mathrm{CaAl}_{2}\left[\mathrm{Si}_{2} \mathrm{O}_{7}\right](\mathrm{OH})_{2} \cdot \mathrm{H}_{2} \mathrm{O}$. Journal of Structural Chemistry, 54, 146-151. 
Larson, A.C. and Von Dreele, R.B. (1994) General Structure Analysis System (GSAS), Los Alamos National Laboratory Report, 86-748.

Lazarev, A.N. (1972) Vibrational Spectra and Structure of Silicates. Consultant Bureau, New York.

LeBail, A., Duroy, H. and Fourquest, J.L. (1988) Ab initio structure determination of $\mathrm{LiSbWO}_{6}$ by X-ray powder diffraction. Materials Research Bulletin, 23, 447-452.

Le Cléac'h, A. and Gillet, P. (1990) IR and Raman spectroscopic study of natural lawsonite. European Journal of Mineralogy, 2, 43-53.

Libowitzky, E. (1999) Correlation of O-H stretching frequencies and $\mathrm{O}-\mathrm{H} \cdots \mathrm{O}$ hydrogen bond lengths in minerals. Monatshefte für Chemie, 130, 1047-1059.

Libowitzky, E. and Armbruster, T. (1995) Low-temperature phase transitions and the role of hydrogen bonds in lawsonite. American Mineralogist, 80, 1277-1285.

Libowitzky, E. and Armbruster, T. (1996) Lawsonite-type phase transition in hennomartinite, $\mathrm{SrMn}_{2}\left[\mathrm{Si}_{2} \mathrm{O}_{7}\right]$ $(\mathrm{OH})_{2} \cdot \mathrm{H}_{2} \mathrm{O}$. American Mineralogist, 81, 9-18.

Libowitzky, E. and Rossman, G.R. (1996) FTIR spectroscopy of lawsonite between 82 and $325 \mathrm{~K}$. American Mineralogist, 81, 1080-1091.

Liebscher, A., Dörsam, G., Franz, G., Wunder, B. and Gottschalk, M. (2010) Crystal chemistry of synthetic lawsonite solid-solution series $\mathrm{CaAl}_{2}\left[(\mathrm{OH})_{2} /\right.$ $\left.\mathrm{Si}_{2} \mathrm{O}_{7}\right] \cdot \mathrm{H}_{2} \mathrm{O}-\mathrm{SrAl}_{2}\left[(\mathrm{OH})_{2} / \mathrm{Si}_{2} \mathrm{O}_{7}\right] \cdot \mathrm{H}_{2} \mathrm{O}$ and the Cmcm$P 2_{1} / m$ phase transition. American Mineralogist, 95, 724-735.

Mejía-Uriarte, E.V., Sato-Berru, R.Y., Navarrete, M., Kolokoltsev, O. and Saniger, J.M. (2012) Determination of phase transition by principal component analysis applied to Raman spectra of polycrystalline $\mathrm{BaTiO}_{3}$ at low and high temperature. Journal of Applied Research and Technology, 10, 57-62.

Mevel, C. and Kienast, J.R. (1980) Chromian jadeite, phengite, pumpellyite, and lawsonite in a highpressure metamorphosed gabbro from the French Alps. Mineralogical Magazine, 43, 979-984.

Meyer, H.W., Marion, S., Sondergeld, P., Carpenter, M.A., Knight, K.S., Redfern, S.A.T. and Dove, M.T. (2001) Displacive components of the low-temperature phase transitions in lawsonite. American Mineralogist, 86, 566-577.

Miyajima, H., Matsubara, S., Miyawaki, R. and Ito, K. (1999) Itoigawaite, a new mineral, the Sr analogue of lawsonite, in jadeitite from the Itoigawa-Ohmi district, central Japan. Mineralogical Magazine, 63, 909-916.

Novak, A. (1974) Hydrogen bonding in solids. Correlation of spectroscopic and crystallographic data. Structure and Bonding (Berlin), 18, 177-216.

Origlieri, M.J., Yang, H., Downs, R.T., Posner, E.S., Domanik, K.J. and Pinch, W.W. (2012) The crystal structure of bartelkeite, with a revised chemical formula, $\quad \mathrm{PbFeGe}^{\mathrm{VI}}\left(\mathrm{Ge}_{2}^{\mathrm{IV}} \mathrm{O}_{7}\right)(\mathrm{OH})_{2} \cdot \mathrm{H}_{2} \mathrm{O}$, isotypic with high-pressure $P 2_{1} / m$ lawsonite. American Mineralogist, 97, 1812-1815.

Pavlov, S.V. (2013) A phenomenological model of phase transitions in lawsonite. Moscow University Physics Bulletin, 68, 139-142.

Pawley, A.R. and Allan, D.R. (2001) A high-pressure structural study of lawsonite using angle-dispersive powder-diffraction methods with synchrotron radiation. Mineralogical Magazine, 65, 41-58.

Pearson, K. (1901) On lines and planes of closest fit to a system of points in space. Philosophical Magazine, 2, 559-572.

Pechini, M.P. (1967) Method of preparing lead and alkaline earth titanates and niobates and coating method using the same to form a capacitor. US Patent 3,330,697.

Petříček, V., Dušek, M. and Palatinus, L. (2006) JANA2006. Institute of Physics, Prague.

Raab, S. (2010) Synthese und Charakterisierung nanoskaliger hydraulisch hochreaktiver Phasen des Portland- und Tonerdezements. PhD thesis, MartinLuther-Universität Halle-Wittenberg, Germany.

Rietveld, H.M. (1967) Line profiles of neutron powderdiffraction peaks for structure refinement. Acta Crystallographica, 22, 151-152.

Salje, E.K.H. and Carpenter, M.A. (2011) Thermally activated proton hopping in lawsonite, the ferroelectric transition at $125 \mathrm{~K}$, and the co-elastic phase transition at 270 K. Journal of Physics: Condensed Matter, 23, 112208.

Salje, E.K.H., Crossley, S., Kar-Narayan, S., Carpenter, M.A. and Mathur, N.D. (2011) Improper ferroelectricity in lawsonite $\mathrm{CaAl}_{2} \mathrm{Si}_{2} \mathrm{O}_{7}(\mathrm{OH})_{2} \cdot \mathrm{H}_{2} \mathrm{O}$ : hysteresis and hydrogen ordering. Journal of Physics: Condensed Matter, 23, 222202.

Sato-Berru, R.Y., Mejía-Uriarte, E.V., Frausto-Reves, C., Villagrán-Muniz, M., Murrieta, S.H. and Saniger, J.M. (2007) Application of principal component analysis and Raman spectroscopy in the analysis of polycrystalline $\mathrm{BaTiO}_{3}$ at high pressure. Spectrochimica Acta, A66, 557-560.

Schmidt, M.W. and Poli, S. (1994) The stability of lawsonite and zoisite at high pressures: experiments in CASH to $92 \mathrm{kbar}$ and implications for the presence of hydrous phases in subducted lithosphere. Earth and Planetary Science Letters, 124, 105-118.

Shannon, R.D. (1976) Revised effective ionic radii and systematic studies of interatomic distances in halides and chalcogenides. Acta Crystallographica, A32, 751-767.

Sheldrick, G.M. (2008) A short history of SHELX. Acta Crystallographica, A64, 112-122.

Sherlock, S.C. and Okay, A.I. (1999) Oscillatory zoned chrome lawsonite in the Tavşanlı Zone, northwest Turkey. Mineralogical Magazine, 63, 687-692.

Sondergeld, P., Schranz, W., Tröster, A., Armbruster, T., Giester, G., Kityk, A. and Carpenter, M.A. (2005) 


\section{T-INDUCED PHASE TRANSITIONS OF Pb-LAWSONITE}

Ordering and elasticity associated with low-temperature phase transitions in lawsonite. American Mineralogist, 90, 448-456.

Tasci, E.S., de la Flor, G., Orobengoa, D., Capillas, C. and Perez-Mato, J.M. (2012) An introduction to the tools hosted in the Bilbao Crystallographic Server. EPJ Web of Conferences, 22, 1-22.
Toby, B.H. (2001) EXPGUI, a graphical user interface for GSAS. Journal of Applied Crystallography, 34, 210-213.

Wondraschek, H. and Müller, U. (2010) International Tables for Crystallography Volume A1: Symmetry Relations Between Space Groups. Second edition, Wiley, New York. 